\title{
Evaluation of Heat Shields from RTS Wright Industries Magnesium and Uranium Beds
}

\author{
P.S. Korinko \\ Materials Technology Section \\ Strategic Materials Technology Division \\ Savannah River Technology Center
}

ISSUED: Aug. 20, 2002

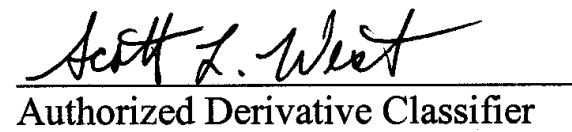

$\frac{8 / 20 / 2002}{\text { Date }}$

SAVANNAH RIVER TECHNOLOGY CENTER, AIKEN, SC 29808

Westinghouse Savannah River Company

Prepared for the U.S. Department of Energy under Contract DE-AC09-96SR18500 
This document was prepared in conjunction with work accomplished under Contract No. DE-AC09-96SR18500 with the U. S. Department of Energy.

\section{DISCLAIMER}

This report was prepared as an account of work sponsored by an agency of the United States Government. Neither the United States Government nor any agency thereof, nor any of their employees, makes any warranty, express or implied, or assumes any legal liability or responsibility for the accuracy, completeness, or usefulness of any information, apparatus, product or process disclosed, or represents that its use would not infringe privately owned rights. Reference herein to any specific commercial product, process or service by trade name, trademark, manufacturer, or otherwise does not necessarily constitute or imply its endorsement, recommendation, or favoring by the United States Government or any agency thereof. The views and opinions of authors expressed herein do not necessarily state or reflect those of the United States Government or any agency thereof.

This report has been reproduced directly from the best available copy.

Available for sale to the public, in paper, from: U.S. Department of Commerce, National Technical Information Service, 5285 Port Royal Road, Springfield, VA 22161, phone: (800) 553-6847, fax: (703) 605-6900

email: orders@ntis.fedworld.gov

online ordering: http://www.ntis.gov/help/index.asp

Available electronically at http://www.osti.gov/bridge

Available for a processing fee to U.S. Department of Energy and its contractors, in paper, from: U.S. Department of Energy, Office of Scientific and Technical Information, P.O. Box 62, Oak Ridge, TN 37831-0062,

phone: (865)576-8401,

fax: (865)576-5728

email: $\underline{\text { reports@ adonis.osti.gov }}$ 
Document: $\quad$ WSRC-TR-2002-00298

Title: $\quad$ Evaluation of Heat Shields from RTS Wright Industries Magnesium and Uranium Beds

$\begin{array}{ll}\text { Keywords } & \text { Mg Beds } \\ & \text { U Beds } \\ & \text { Radiant Heating } \\ & \text { TEF } \\ & \text { Coatings }\end{array}$

APPROVALS

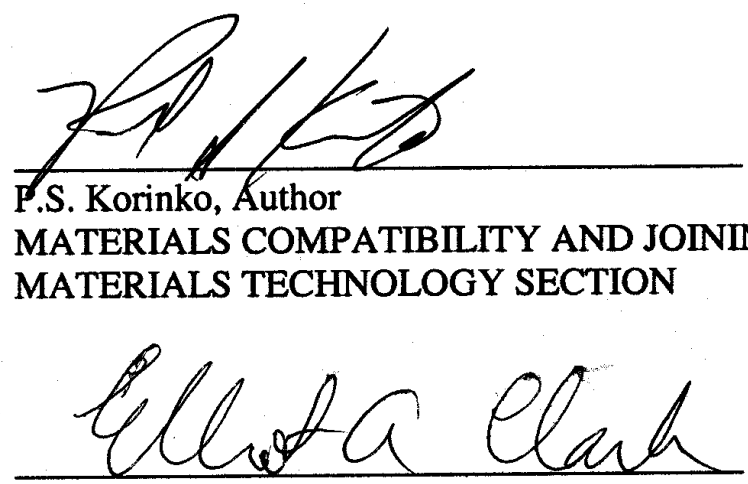

E.A. Clark, Technical Reviewer MATERIALS COMPATIBILITY AND JOINING TECHNOLOGY GROUP

DATE: $8-20.02$ MATERIALS COMPATIBILITY AND JOINING TECHNOLOGY GROUP MATERIALS TECHNOLOGY SECTION

\section{MATERIALS TECHNOLOGY SECTION}
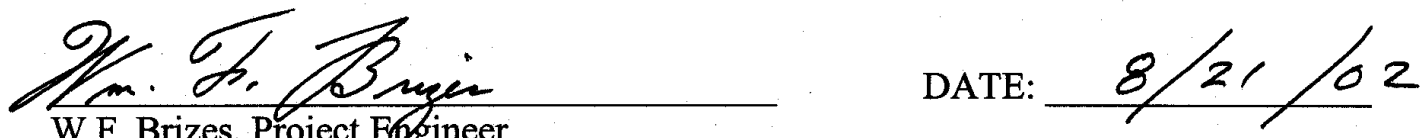

\section{DP PROJECT START-UP}

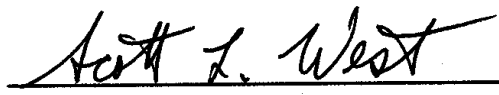

DATE: $8 / 20 / 2002$

S. L. West, Manager MATERIALS COMPATIBILITY AND JOINING TECHNOLOGY GROUP

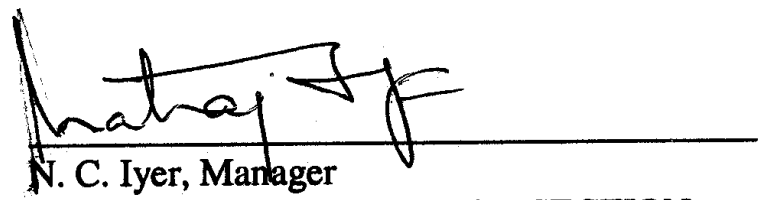

DATE: $\quad 8 / 23 / 02$ 


\section{List of Figures}

Fig. 1. Schematic cross-section of the Mg- U- bed design .6

Fig. 2. Visual appearance of the surface of the mini-wing heat shield, both sides. All coated with $\mathrm{ZrN}$ and subjected to factory testing 7

Fig. 3. Visual appearance of the surfaces of the mini-shields. .8

Fig. 4. Optical micrograph of coating cross-section, etched electrolytically with oxalic acid, 500 $\mathrm{X}$ magnification.

Fig. 5. SEM image showing an overall view of $\mathrm{ZrN}$ coated surface of a mini-wing heat shield (a) blue side (b) lighter shiny side.

Fig. 6. XEDS plot from a region of the mini-heat shield that was blue, $10 \mathrm{kV}$ accelerating voltage, (a) flat surface, large area (b) expanded y-axis same scan as above.

Fig. 7. XEDS plot from a region of the mini-heat shield that was gold, $15 \mathrm{kV}$ accelerating voltage, (a) flat surface, large area (b) expanded y-axis same scan as above.

Fig. 8. XEDS plot from a region of the mini-heat shield that was gold, $10 \mathrm{kV}$ accelerating voltage, (a) flat surface, large area (b) expanded y-axis same scan as above.

Fig. 9. XEDS plot from a region of the mini-heat shield that was gold, $15 \mathrm{kV}$ accelerating voltage, (a) flat surface, large area (b) expanded y-axis same scan as above.........................13

Fig. 10. SEM micrograph of surface of $\mathrm{ZrN}$ coated sample that exhibited a (a) near metallic white sheen (b) near metallic white sheen and (c) a blue oxide film. XEDS data for each spot are shown in Figure 11

Fig. 11. XEDS plots of spots shown in Fig. 10, (a) spot 1, (b) spot 2, (c) spot 3, (d) spot 4, (e) spot 5 , and (f) spot 6 .

Fig. 12. AES composition profile of $\mathrm{ZrN}$ coated heat shield that exhibited (a) gold coloration (b) blue coloration.

Fig. 13. AES composition profile from gold mini-heat shield (a) oxide to nitride transition (b) nitride to base metal transition.

Fig. 14. AES composition profile from blue mini-heat shield (a) oxide to nitride transition (b) nitride to base metal transition. 


\title{
Evaluation of Heat Shields from RTS Wright Industries Magnesium and Uranium Beds
}

\author{
P.S. Korinko
}

\section{SUMMARY}

Heat shields from a factory test of the furnaces that will be used to heat the magnesium and uranium beds for the tritium extraction facility (TEF) were examined to determine the cause of discoloration. The samples were examined using visual, optical microscopy, electron microscopy, x-ray spectroscopy, and Auger electron spectroscopy. The coating had the expected surface related growth anomalies. The surface discoloration was caused by oxidation. There was also evidence of minor aluminum contamination. It is expected that the heat shields will continue to degrade and ultimately result in a gray-body emissivity of about 0.5 . This will adversely affect the radiant heat transfer to the vessel. A low emissivity noble metal or alloy coating or monolith is recommended as an alternate first shield material.

\section{BACKGROUND}

RTS Wright Industries (Wright) is fabricating new magnesium and uranium bed heaters for the tritium extraction facility (TEF). These beds are designed with a permeation barrier coating on both the internal and external surfaces of the inner vessel (cartridge). The inner vessel is heated using radiant heating, heating elements are backed by radiant heat transfer shields of polished stainless steel coated with a reflective coating, see Fig. 1. Numerous coatings were tested, including titanium nitride, zirconium nitride and electroless nickel. There are three (3) heat shields in each heat shield pack. During operation, the annular space is evacuated to a vacuum on the order of $100 \mathrm{~m}$ Torr. In order to test the system, the retort was heated to $600^{\circ} \mathrm{C}$ using the radiant heater design. This design is different from previous designs that had significantly more heater elements. The intent of this new heating system is to reduce the heat load to the glove box.

Several tests were conducted using the various coated heat shields. In all cases, the originally shiny shields were discolored. The surfaces remained reflective but exhibited heat tints that ranged from golden to purple. It is anticipated that additional exposure to the annular vacuum conditions will result in a surface that is no longer as reflective. This increase in emissivity will likely reduce the thermal efficiency of the heater and subsequently increase the heat load into the glove box and may preclude the inner vessel from reaching its required operating temperature. If this occurs, additional operating expenses will be encountered by the TEF due to removal and replacement of magnesium and uranium beds and heaters. A $\mathrm{ZrN}$ coated heat shield, and two mini-heat shields were submitted to the Materials Compatibility and Joining Technology Group (MCJTG) for evaluation. 


\section{EVALUATION METHODS}

The $\mathrm{ZrN}$ coated samples were visually examined to determine the variation in color.

Optical microscopy was used to examine cross-sections of the coating and surface discoloration. Surface roughness and the presence of voids and coating defects were also examined.

Scanning electron microscopy (SEM) analysis was used to determine surface topography, estimate coating thickness and provide gross chemical analysis of the surface. The SEM microchemistry results were obtained using x-ray energy dispersive spectroscopy (XEDS).

Auger electron spectroscopy (AES) was used to determine the surface chemistry. Scanning electron images and backscatter electron images of the sputtered areas were also obtained.

\section{RESULTS}

Visual examination of the heat shield revealed discoloration that ranged from dark gold to purple. The surfaces retained a "glossy" appearance despite the discoloration. Optical photographs of the surface are shown in Figs. 2 and 3, of the mini-wing and mini-shield, respectively. These photographs exhibit color variations, the large heat shield exhibits a dark gold to dark blue coloration. The variation from end to end is a consequence of the temperature variation within the furnace.

Metallographic examination of the coating cross-section did not reveal evidence of surface attack. The cross-section revealed a compact coating with a few expected growth defects, Fig. 4.

Scanning electron microscopy of the coating surface revealed crater-like defects, Fig. 5. These defects are likely due to surface burnishing, either as a matter of post-coating processing or simple handling. The surface exhibits these craters and some positive coating defects. The positive defects are typically caused by a subsurface anomaly that disrupts the growth morphology. The side of the mini-wing heat shield that was exposed to the heater element did not exhibit as many positive-coating anomalies as the backside.

$\mathrm{X}$-ray energy dispersive spectroscopy on the surfaces of the heat shields revealed that the $\mathrm{ZrN}$ coating was sufficiently thin to have the substrate interfere with the surface analysis. The largest peak is due to zirconium. The substrate elements of iron, chromium and nickel that were detected had peak heights that were dependent on the accelerating voltage and the coating thickness, compare Fig. 6a to Fig. 7a and Fig. 8a to Fig. 9a. This condition would not be an issue, except that the $\mathrm{Cr}-\mathrm{L}_{\beta 1}$ interferes with the oxygen peak, which confounds the data and makes resolution difficult where the oxide layer is thin, as in the gold discolored heat shield XEDS scan shown in Fig. 9b. At relatively low accelerating voltages, however, the interaction volume is reduced so the coating substrate interactions are minimized. Oxygen is clearly visible in the blue discolored heat shield sample, Fig. 6 and less visible in the gold discolored sample, Fig. 8. The vendor had speculated that the discoloration was due to aluminum migration, so aluminum was specifically examined. An aluminum peak is identified, however, it is just above 
the background. It is suspected that the detection of aluminum may be due to its presence as part of the SEM fixtures rather than being present on the surface of the sample.

In addition, the surface condition that exhibited features of interest was analyzed. The electron images of the surfaces that were shiny and blue are shown in Fig. 10. The different spots are marked 1 - 6 with the XEDS results in Figs. 11a - 11f. The depressions in Figs. 10a and 10c, spots 1 and 4, exhibit little or no zirconium, only zirconium was detected at spots 2 and 3, while a mixture of zirconium and stainless steel were detected at spots 5 and 6 . Aluminum is identified on these XEDS plots, but no explanation is obvious.

Auger electron spectroscopy is a powerful surface analysis and coating evaluation technique. Using AES the elements, and in some cases the valence state, present from about 50 angstroms ( $\AA)$ to $25,000 \AA(1 \AA=0.1 \mathrm{~nm})$ were determined. A preliminary scan did not support the XEDS near surface contamination due to aluminum, even though aluminum was specifically sought. The only contaminant detected was oxygen as shown in Figs. 12a and 12b, and Figs. 13a and 14a. The near surface data for the zirconium peak exhibited a shift in energy due to a valence of four vs. two for the oxide and nitride phases, respectively which can be seen in Figs. 13a and 14a. The thickness of the oxide layer was about $400 \AA$ for the gold discolored surface, Figs. 12a and 13a and $900 \AA$ for the blue discolored surface, Figs. 12b and 14a.

The depth profile of selected elements for both the blue and gold heat tinted heat shield areas are shown in Fig. 12. Only zirconium and nitrogen are detected through the bulk of the coating. The aluminum scan is in the same level as the noise, which suggests that it, is not present in adequate quantities to be considered. Carbon is present at the surface, Figs. 13a and 14a, and is a very common surface contaminant detected by AES. Depth profiles exhibit a transition at the surface from zirconium and oxygen to zirconium and nitrogen beyond the oxide transition depth.

Another interesting result that was observed was that several of the samples that were examined exhibited the opposite transition, i.e., that of $\mathrm{ZrN}$ to $\mathrm{ZrO}_{2}$, at the metal coating interface. This is apparent from the data presented in Figs. 12a, 12b, and 14b, while not all of the samples exhibited this transition, Fig. 13b, although these data indicate an increase in carbon content near the surface. The cause of these variations was not determined.

\section{DISCUSSION AND CONCLUSIONS}

The surface discoloration is caused primarily by oxidation. A review of the vendor test report indicates that many of the appropriate steps were taken to minimize oxygen ingress. The multiple evacuate and backfill procedure should have helped prevent significant oxidation. Unfortunately, a leak rate test was not conducted. This data would help define the best practice for resolution of the oxidation issue. In addition, this testing was conducted using continuous pumping and vacuum significantly better than what is expected for the production TEF heater beds.

Aluminum contamination on the surface of the discolored heat shield was detected based on the SEM XEDS results but not confirmed with AES. The AES is a more sensitive instrument to detect surface contamination than the SEM using XEDS. It is suspected that the aluminum is an 
artifact of the analysis technique rather than actually being present as a contaminant. The speculation that the discoloration was caused by aluminum vaporization is difficult to concur with since the partial pressure of aluminum at $600^{\circ} \mathrm{C}$ is expected to be less than $10^{-10} \mathrm{~atm}(7.6 \mathrm{x}$ $10^{-8}$ torr). Thus, there is a significant backpressure to minimize aluminum vaporization. Aluminum vaporization in vacuum systems can be significant at higher temperatures.

Additional testing which might be possibly used to determine the extent of oxygen contamination in the annulus would include evacuating and heating the chamber to determine the gaseous species being evolved and determining the gas composition using a mass spectrometer. Aluminum would likely not be detected using this method since it would condense on the cool surfaces of the detector.

Virtually any material that forms a tenacious, oxide scale will discolor under the conditions that have been tested, $600^{\circ} \mathrm{C}$ and pressure of $50 \mathrm{mTorr}$. In order to avoid changing the spectral reflectance of the surface, a lower oxygen pressure needs to be established or a "non-scaling" noble metal must be used. The operating temperature of the bed is nominally $475^{\circ} \mathrm{C}$. This temperature is needed to ensure rapid enough reaction rates and efficiency. Since the water cracking is a thermally driven process, a change in temperature of $15^{\circ} \mathrm{C}$ will typically result in a change of reaction rate of a factor of two (general rule of thumb for Arrehenius reactions).

It is expected that the surface oxidation of the heat shields will continue, especially since the TEF will use a passive vacuum system. The emissivity is expected to increase. This will decrease the radiant heat transfer into the inner vessel, (cartridge). This degradation will likely increase the power requirements for the heaters and result in increased outer vessel temperatures.

\section{RECOMMENDATIONS}

\section{Testing:}

- Measure the leak rate of the outer vacuum chamber; the testing with continuous evacuation of the annulus does not duplicate the anticipated TEF operating conditions.

- Determine gas species present during operation using mass spectrometry.

- Decrease test temperature. The operating temperature for the beds is about $475^{\circ} \mathrm{C}$. A test temperature of $530^{\circ} \mathrm{C}$ provides a $50^{\circ} \mathrm{C}$ over-temperature condition, thus lowering it beyond this is not feasible.

\section{Fabrication:}

- Utilize a more noble coating or substrate for the first shield. Two materials that will likely work well are gold or platinum plating or thin sheets. The use of gold-nickel braze alloy at this temperature has been reported (ASM Metals Handbook, Volume 6, Brazing, Soldering and Welding, Ninth Edition). There are three possible degradation modes, interdiffusion of the plated element into the stainless steel surface which would reduce the emissivity, gold or platinum oxide vaporization and the loss of the coating, and coating grain growth with 
subsequent coating breaches and substrate oxidation. Recent searches have revealed an aluminum based low emissivity coating that may also be useful.

- Incorporate a getter material into the cartridge surface. This addition could be made by adding a sheet of oxygen getter material to the side or bottom of the $\mathrm{Mg} / \mathrm{U}$ cartridge. It would decrease the oxygen partial pressure to a value significantly lower than that achievable by mechanical vacuum systems.

- Polish the inner wall of the outer vessel to decrease its emissivity. This change may help reduce the outer wall temperature by increasing the thermal reflective surfaces.

- Increase the emissivity of the outer wall of the inner vessel. This can be accomplished by "blackening" the surface or by roughening it. The surface could be "blackened" using a thermal oxidation treatment. Both grit blasting or oxidation of the surface may promote oxygen adsorption and cause increased heat shield oxidation.

- Improve the vacuum to high vacuum values with minimal external gas ingress. Use a turbopump or the like to ensure a vacuum of $10^{-5}$ torr. This will decrease the oxidation rate somewhat, but an oxide film is still possible.

- Eliminate the outer aluminide coating on the $\mathrm{Mg}$ bed cartridge. This coating surface is not perfectly smooth and offers areas for oxygen to adsorb. The desorbing oxygen acts as a virtual source for subsequent oxidation.

\section{ACKNOWLEDGEMENTS}

The author would like to thank the TEF project for supporting this evaluation. He would also like to thank Zane Nelson and Cindy Foreman for metallographic support. The efforts of Jack Durden for SEM and XEDS work are also appreciated. Finally, the author would like to acknowledge the efforts and support of Don Blankenship for the Auger electron spectroscopy. 


\section{C : SECTION OF INNER REACTOR VESSEL, HEATER, SHIELD AND OUTER VESSEL}

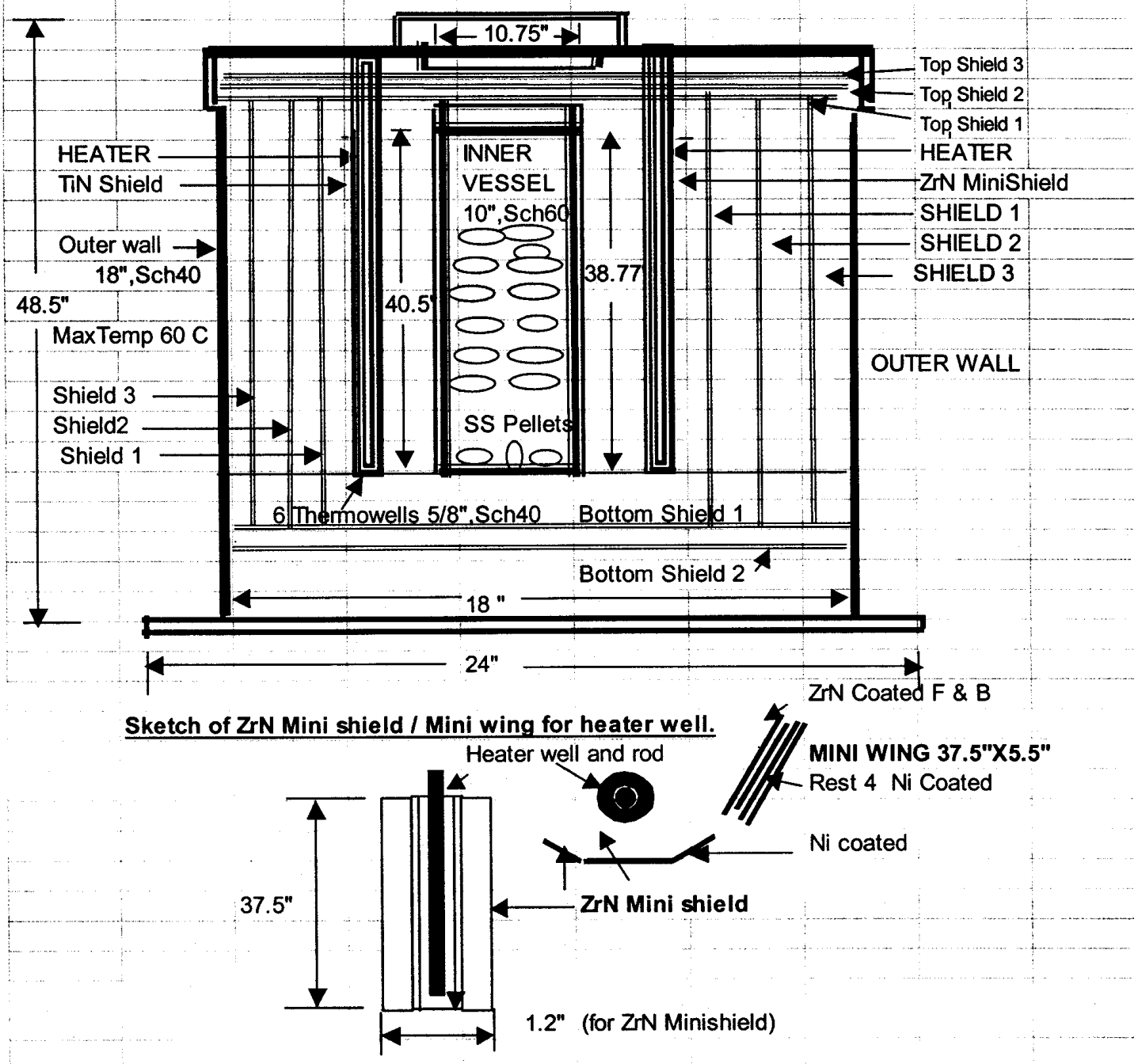

Fig. 1. Schematic cross-section of the Mg- U- bed design. 

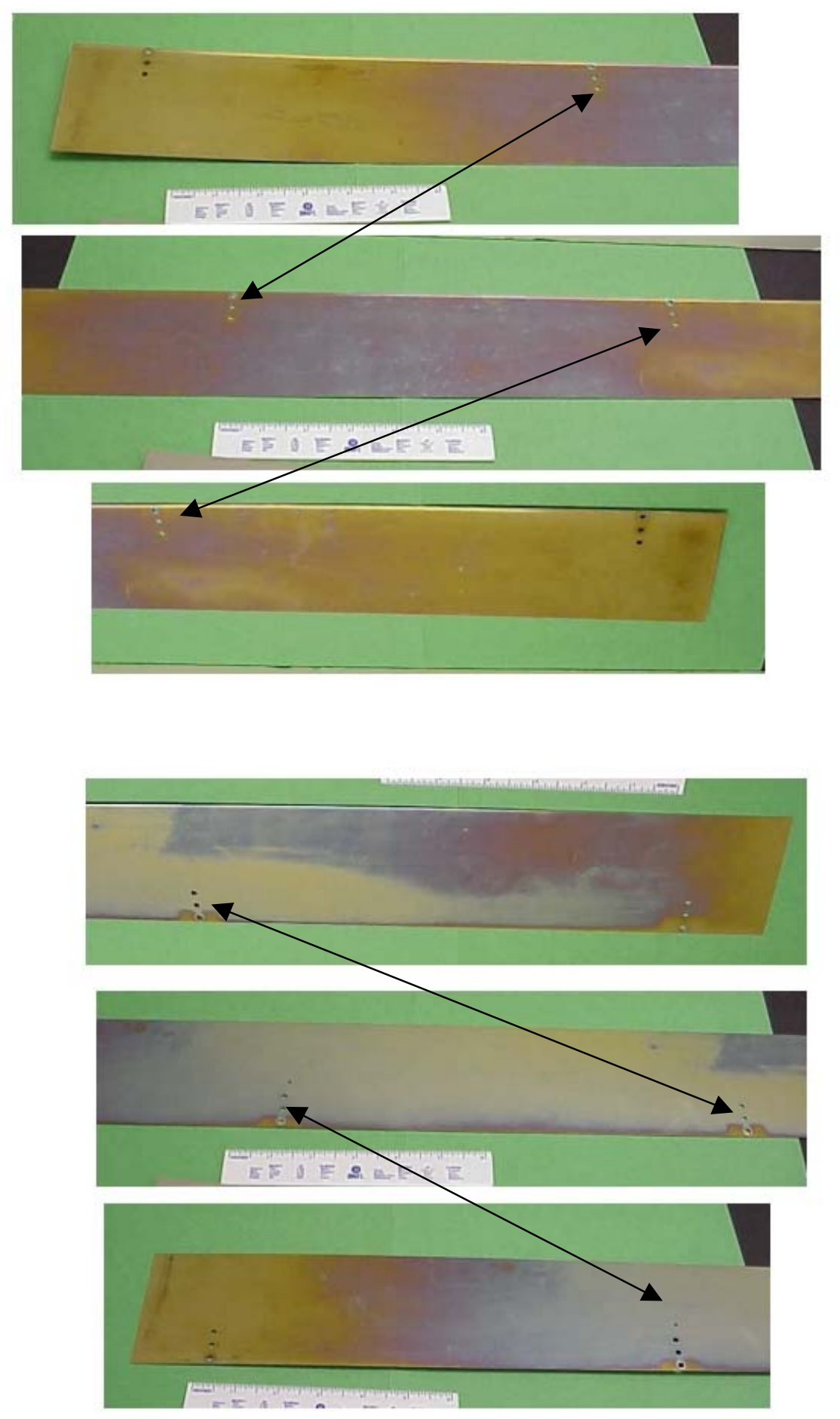

Fig. 2. Visual appearance of the surface of the mini-wing heat shield, both sides. All coated with $\mathrm{ZrN}$ and subjected to factory testing. 

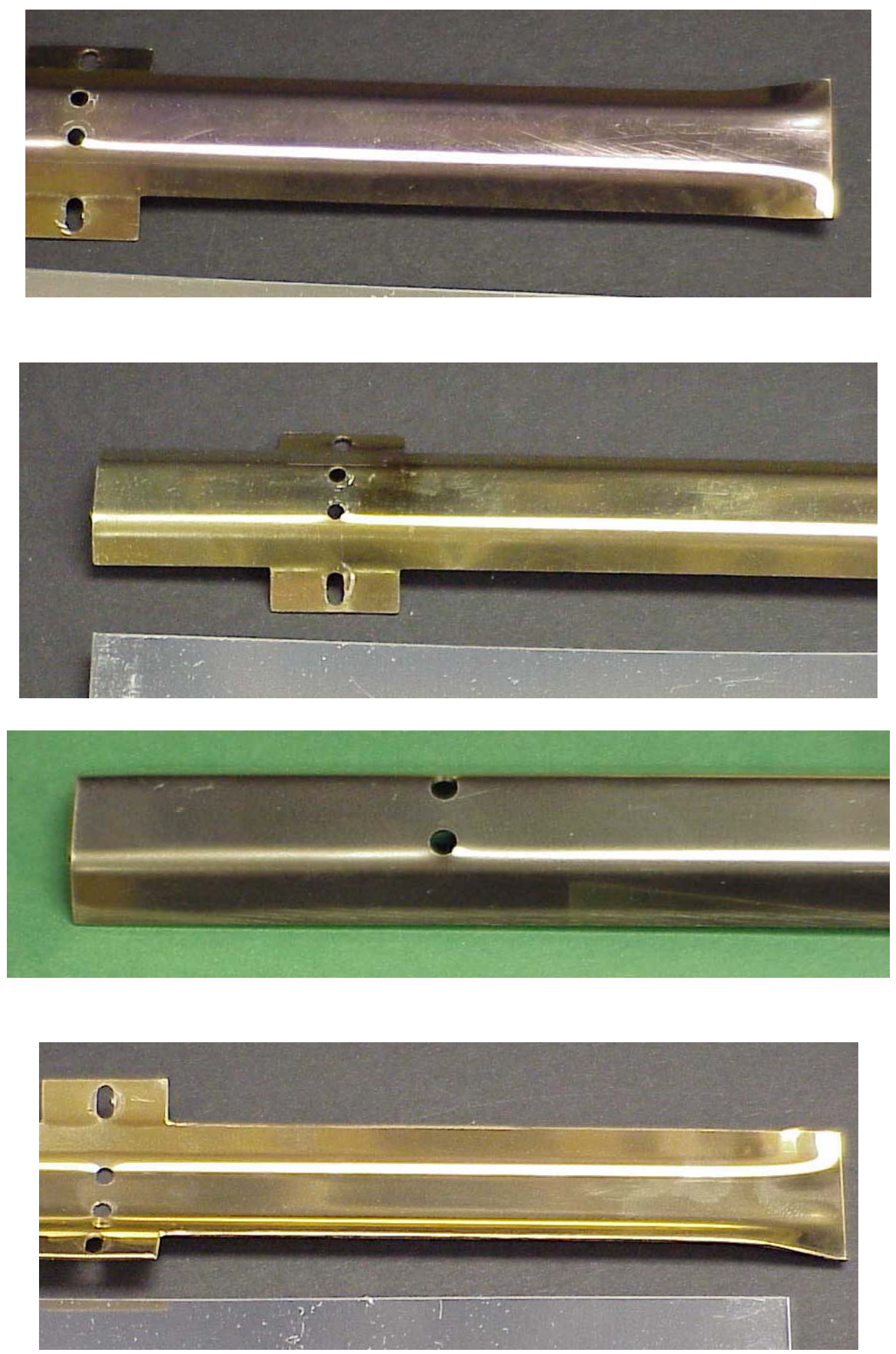

Fig. 3. Visual appearance of the surfaces of the mini-shields. 


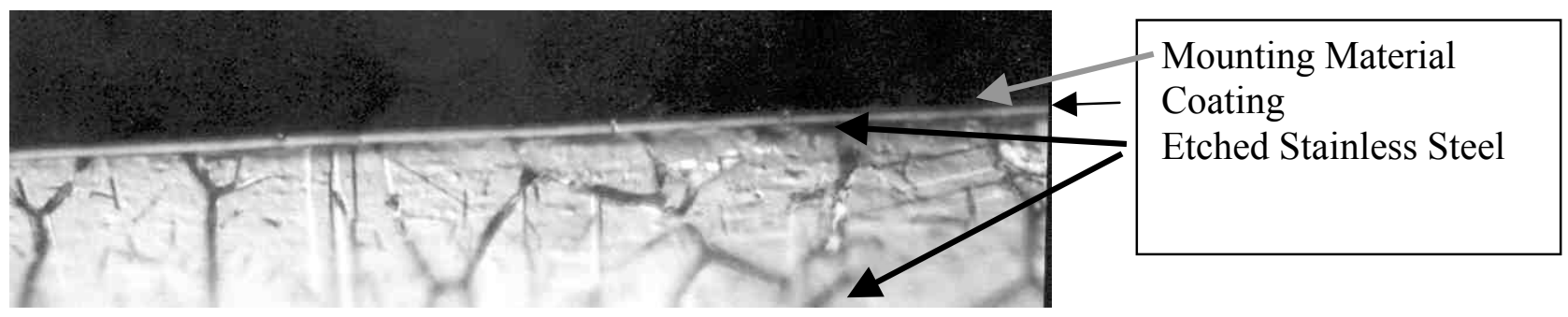

Fig. 4. Optical micrograph of coating cross-section, etched electrolytically with oxalic acid, 500 $\mathrm{X}$ magnification.

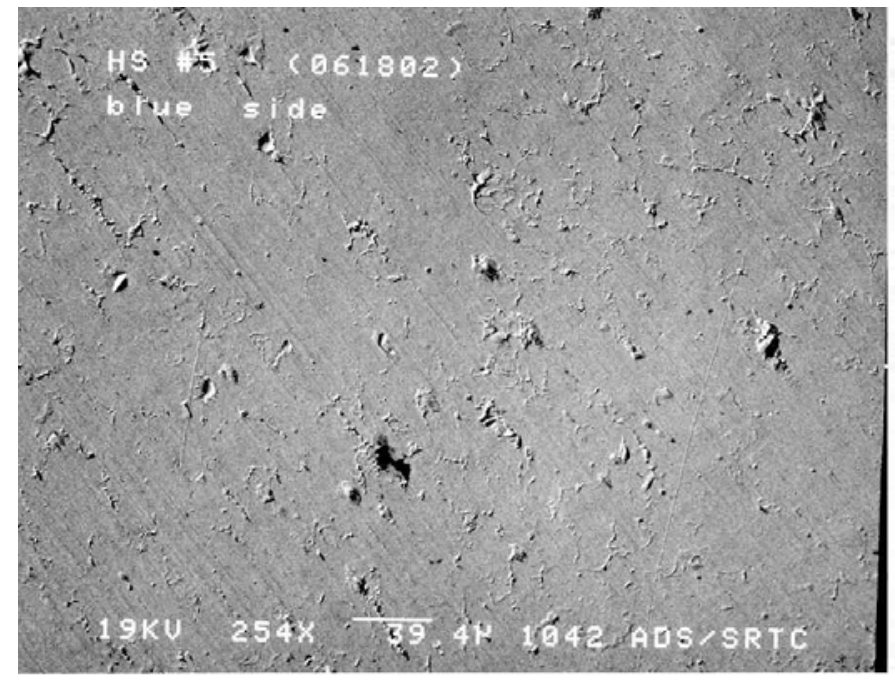

Fig. 5a. SEM image showing an overall view of $\mathrm{ZrN}$ coated surface of a mini-wing heat shield blue side.

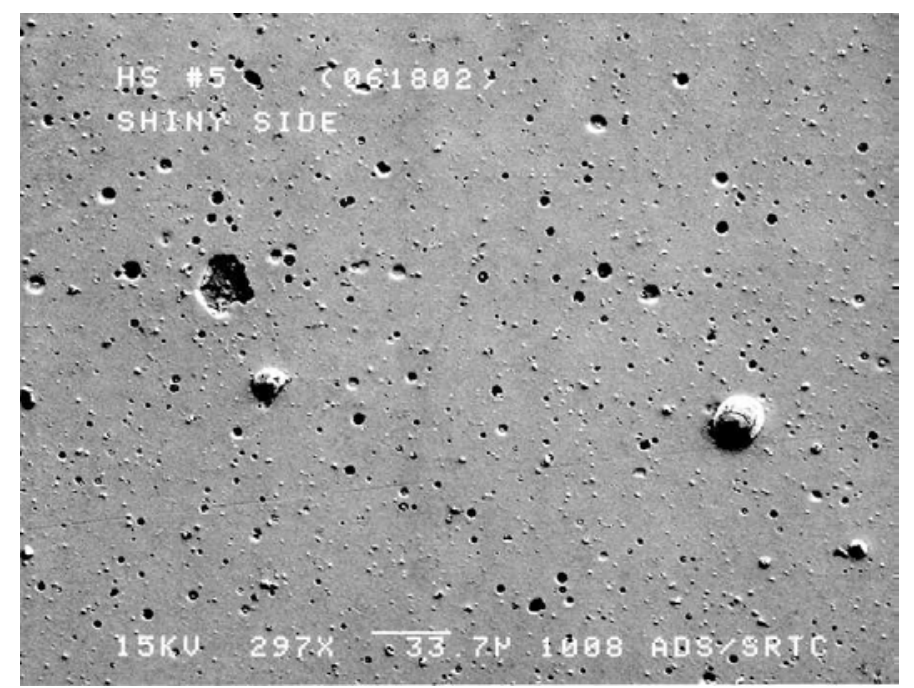

Fig. 5b. SEM image showing an overall view of $\mathrm{ZrN}$ coated surface of a mini-wing heat shield lighter shiny side.

Fig. 5. SEM image showing an overall view of $\mathrm{ZrN}$ coated surface of a mini-wing heat shield (a) blue side (b) lighter shiny side. 
Thermo NORAN

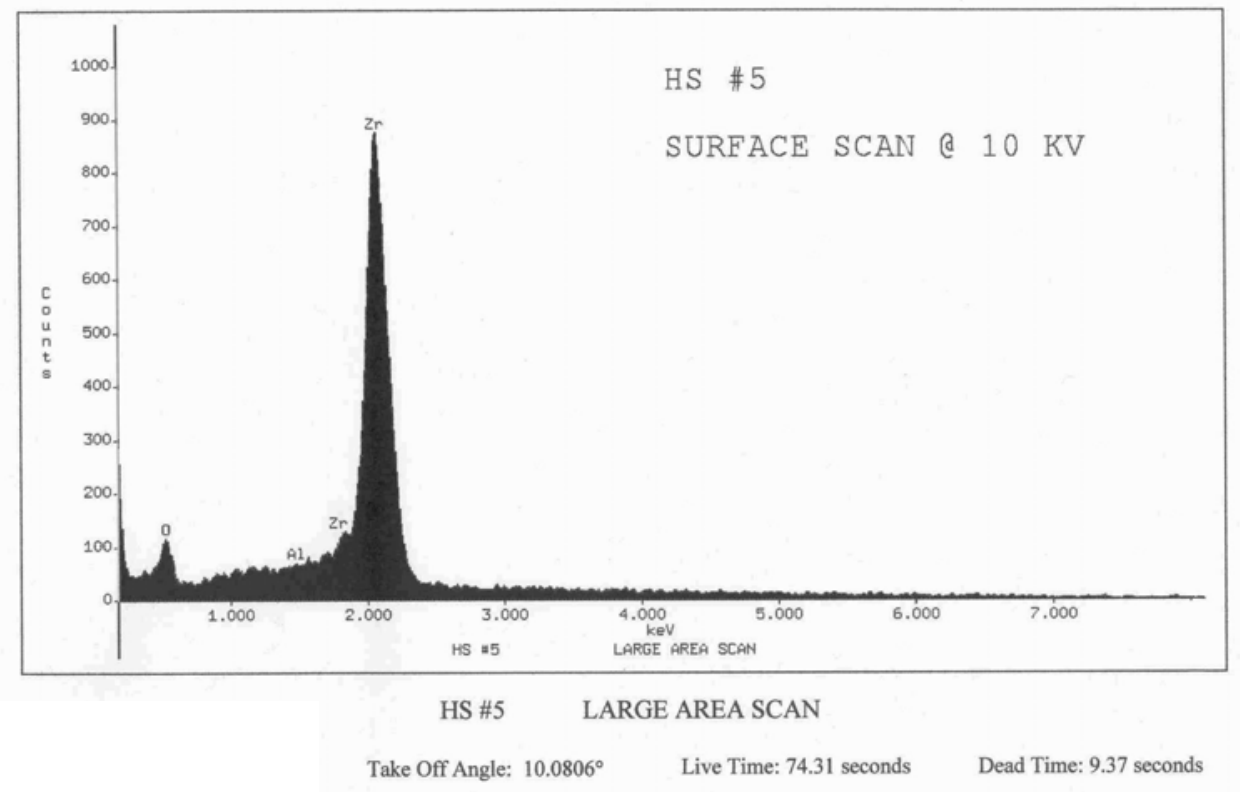

Fig. 6a. XEDS plot from a region that was blue, $10 \mathrm{kV}$ accelerating voltage, flat surface, large area.

Thermo NORAN

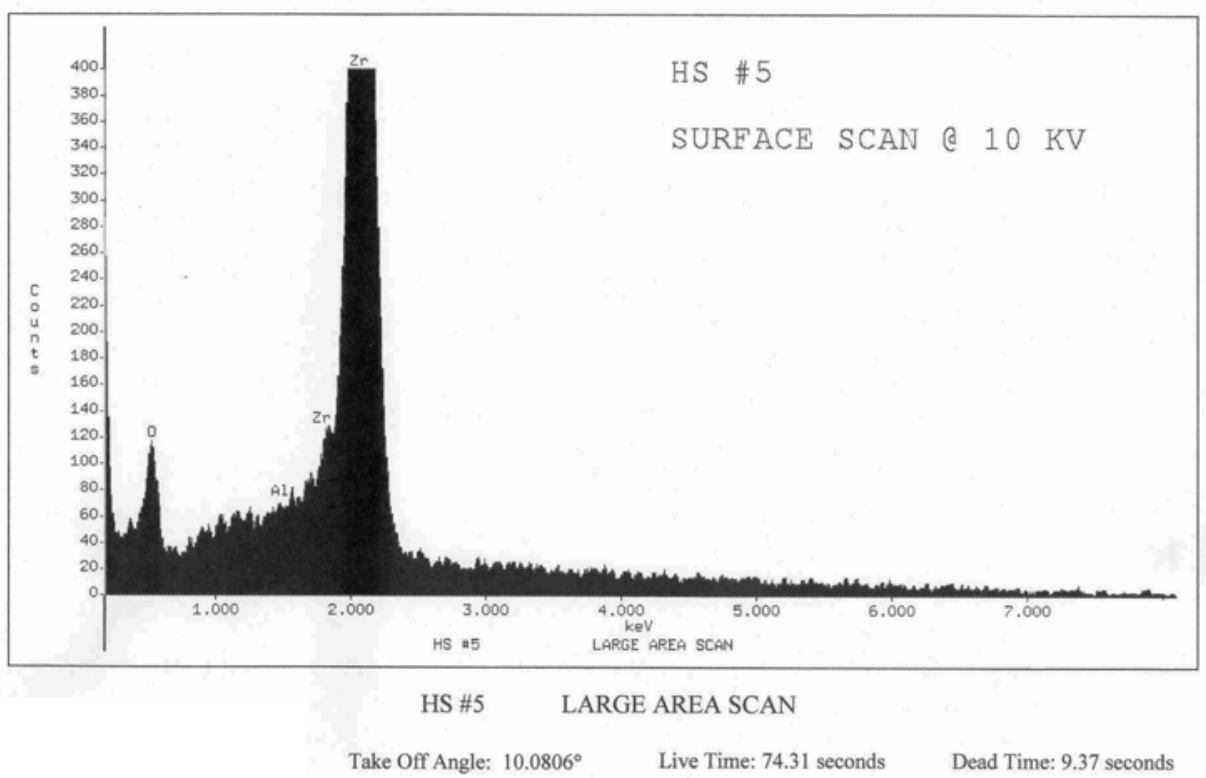

Fig. 6b. XEDS plot from a region that was blue, $10 \mathrm{kV}$ accelerating voltage, flat surface, large area, expanded y-axis same scan as above.

Fig. 6. XEDS plot from a region of the mini-heat shield that was blue, $10 \mathrm{kV}$ accelerating voltage, (a) flat surface, large area (b) expanded y-axis same scan as above. 
Thermo NORAN

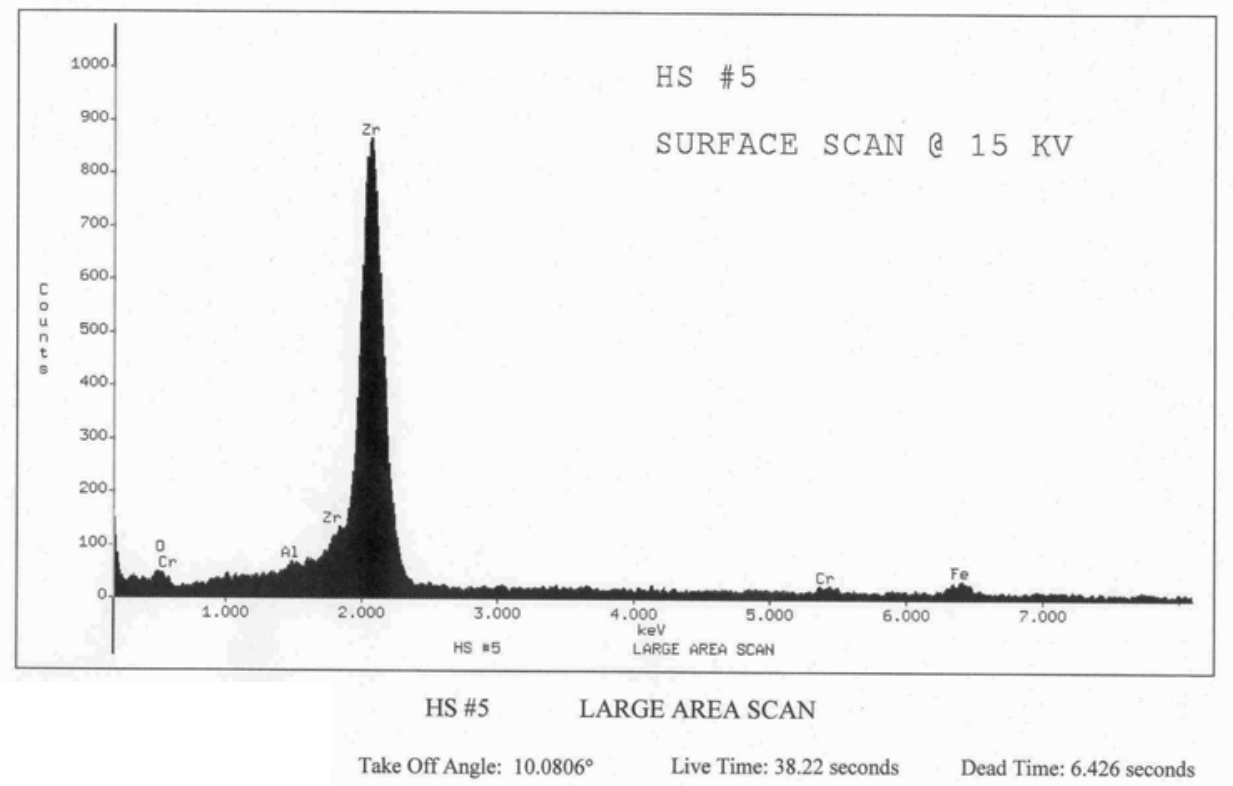

Fig. 7a. XEDS plot from a region that was blue, $15 \mathrm{kV}$ accelerating voltage, flat surface, large area.

Thermo NORAN

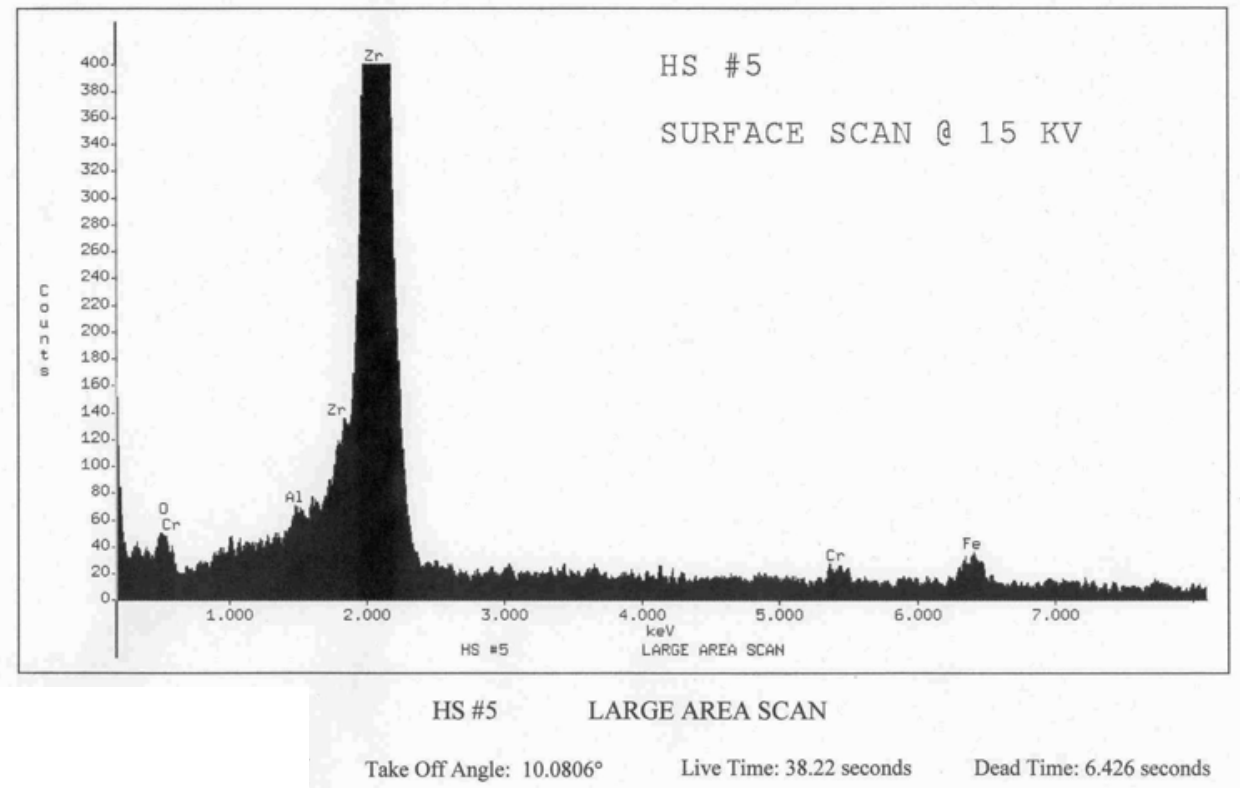

Fig. 7b. XEDS plot from a region that was blue, $15 \mathrm{kV}$ accelerating voltage, flat surface, large area, expanded y-axis same scan as above.

Fig. 7. XEDS plot from a region of the mini-heat shield that was gold, $15 \mathrm{kV}$ accelerating voltage, (a) flat surface, large area (b) expanded y-axis same scan as above. 
ThermoNORAN

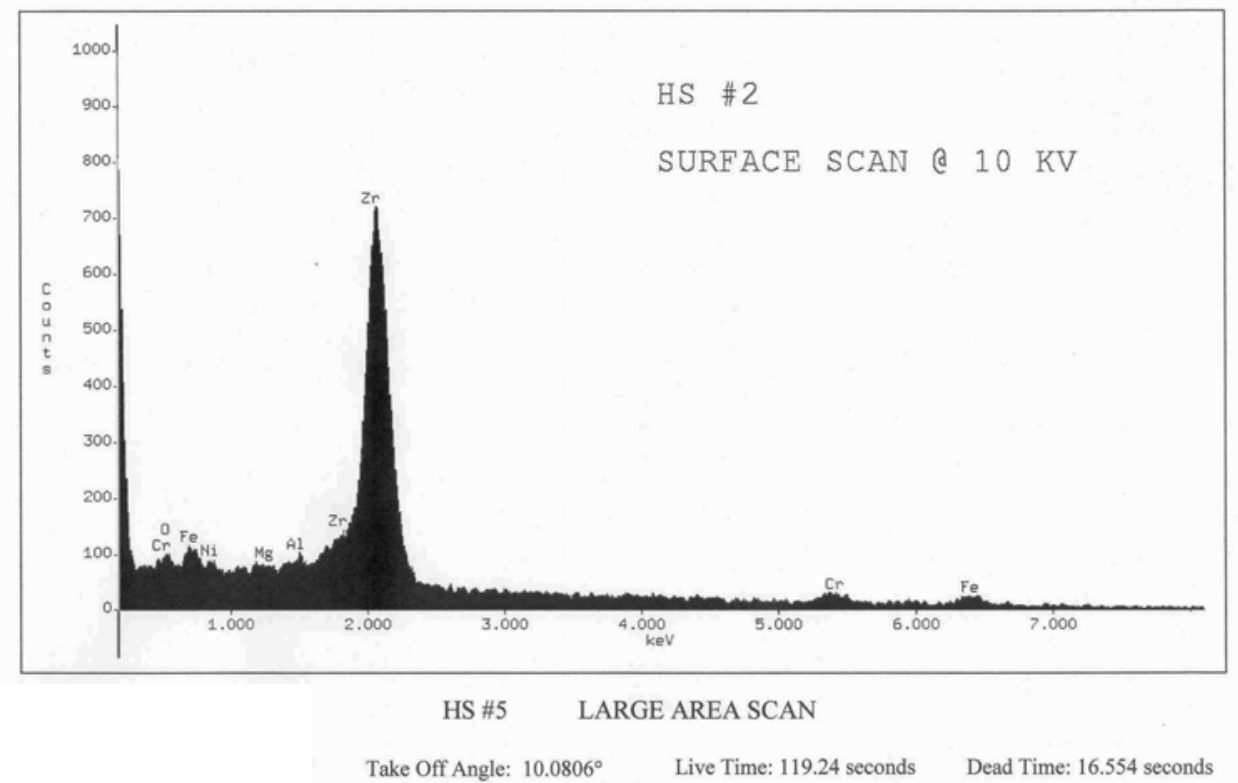

Fig. 8a. XEDS plot from a region that was gold, $10 \mathrm{kV}$ accelerating voltage, flat surface, large area.

Thermo NORAN

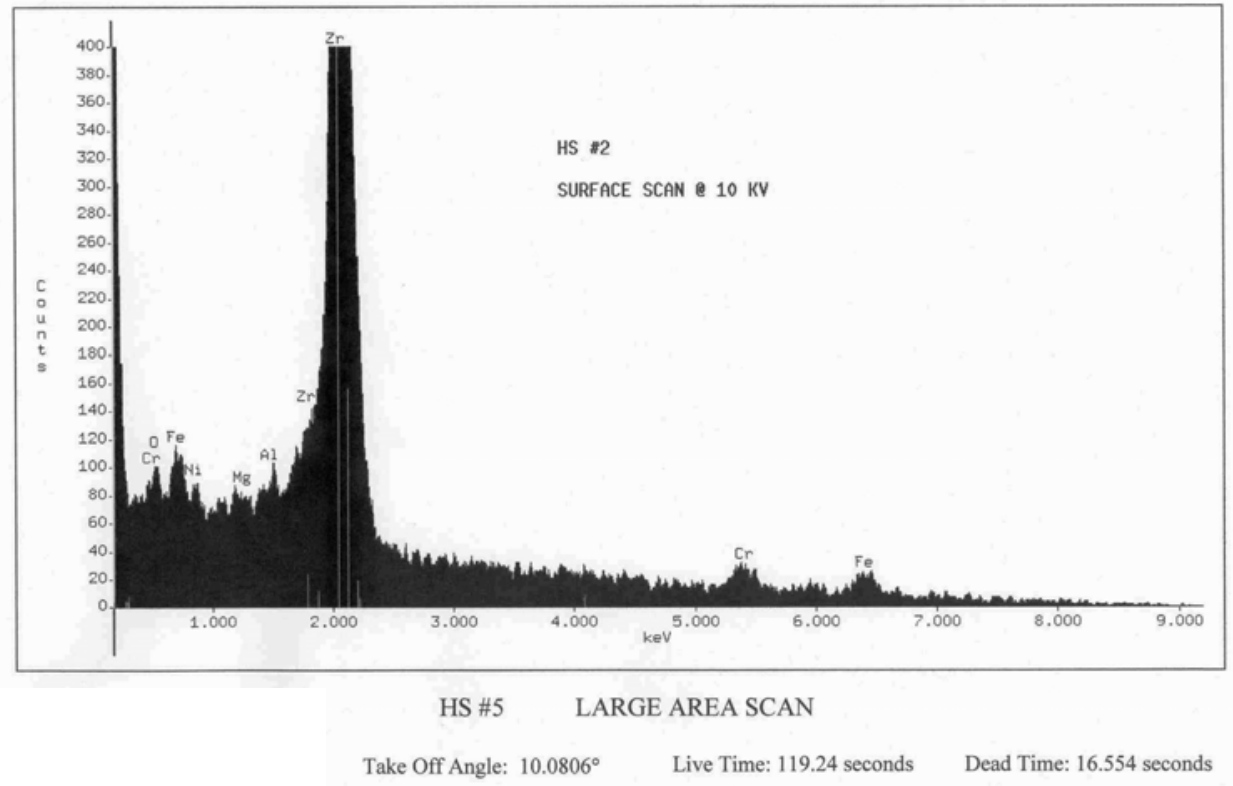

Fig. 8b. XEDS plot from a region that was gold, $10 \mathrm{kV}$ accelerating voltage, flat surface, large area, expanded y-axis same scan as above.

Fig. 8. XEDS plot from a region of the mini-heat shield that was gold, $10 \mathrm{kV}$ accelerating voltage, (a) flat surface, large area (b) expanded y-axis same scan as above. 
Thermo NORAN

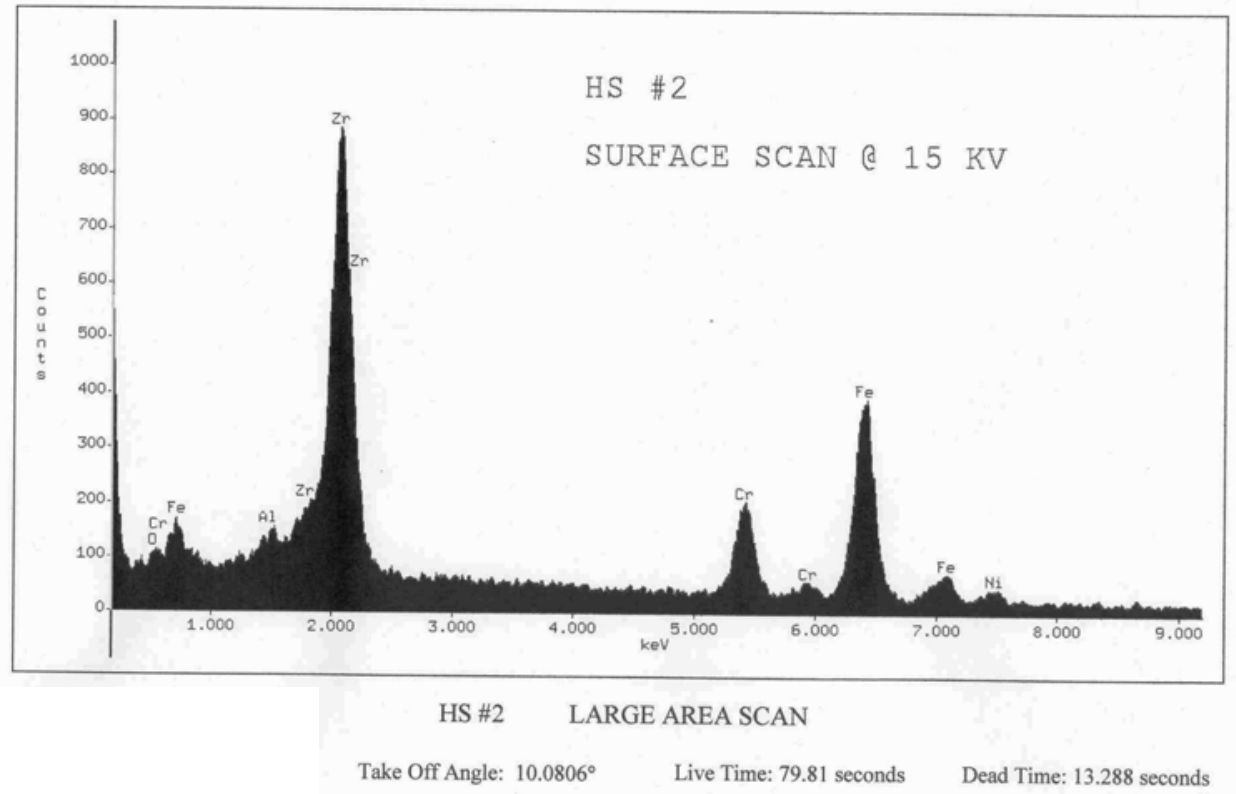

Fig. 9a. XEDS plot from a region that was gold, $15 \mathrm{kV}$ accelerating voltage, flat surface, large area.

Thermo NORAN

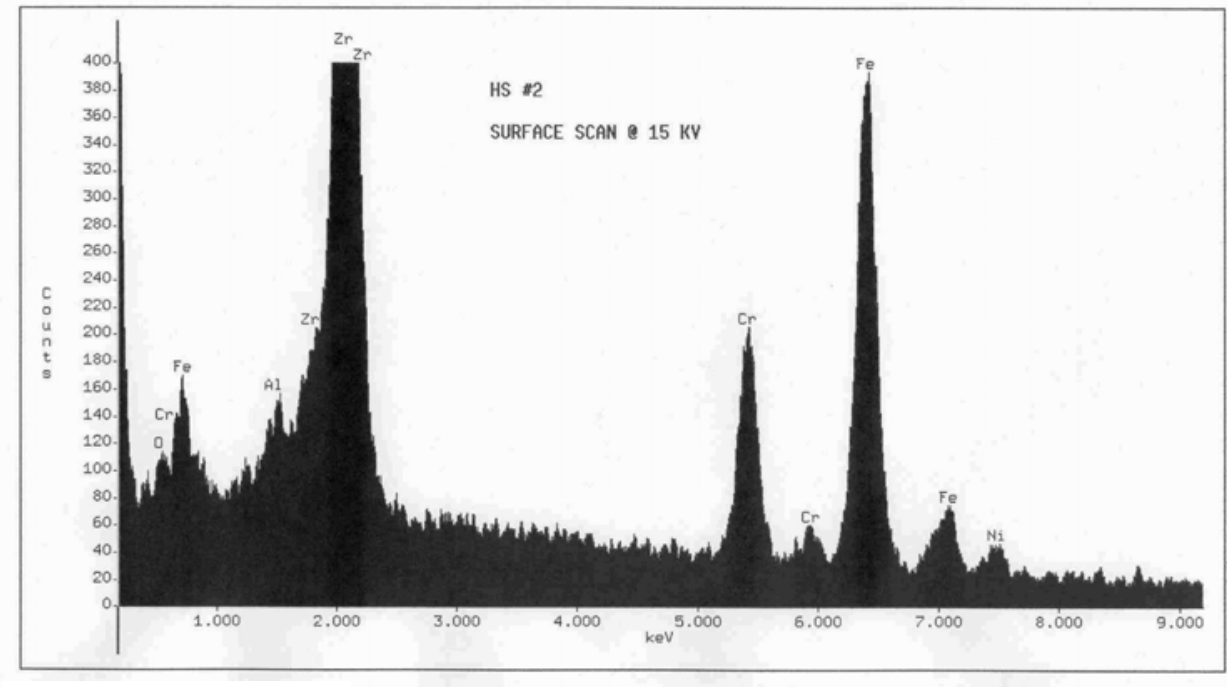

HS \#2 LARGE AREA SCAN

Take Off Angle: $10.0806^{\circ}$ Live Time: 79.81 seconds Dead Time: 13.288 seconds

Fig. 9b. XEDS plot from a region that was gold, $15 \mathrm{kV}$ accelerating voltage, flat surface, large area, expanded y-axis same scan as above.

Fig. 9. XEDS plot from a region of the mini-heat shield that was gold, $15 \mathrm{kV}$ accelerating voltage, (a) flat surface, large area (b) expanded y-axis same scan as above. 


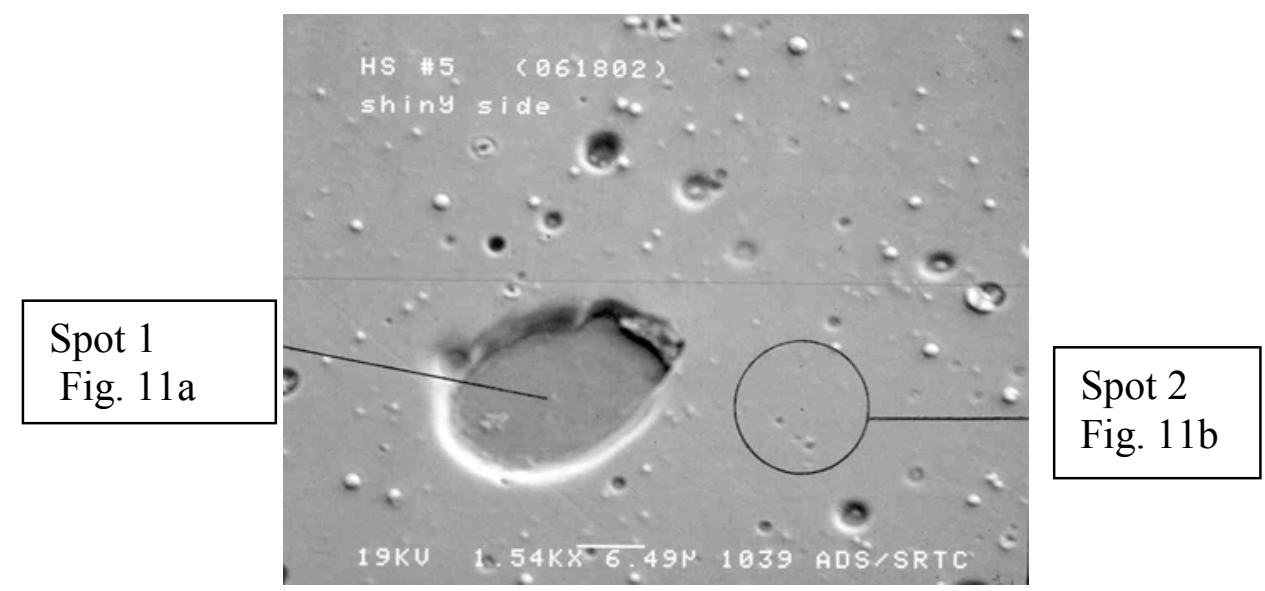

Fig 10a. SEM image of surface of $\mathrm{ZrN}$ coated sample that exhibited a near metallic white sheen

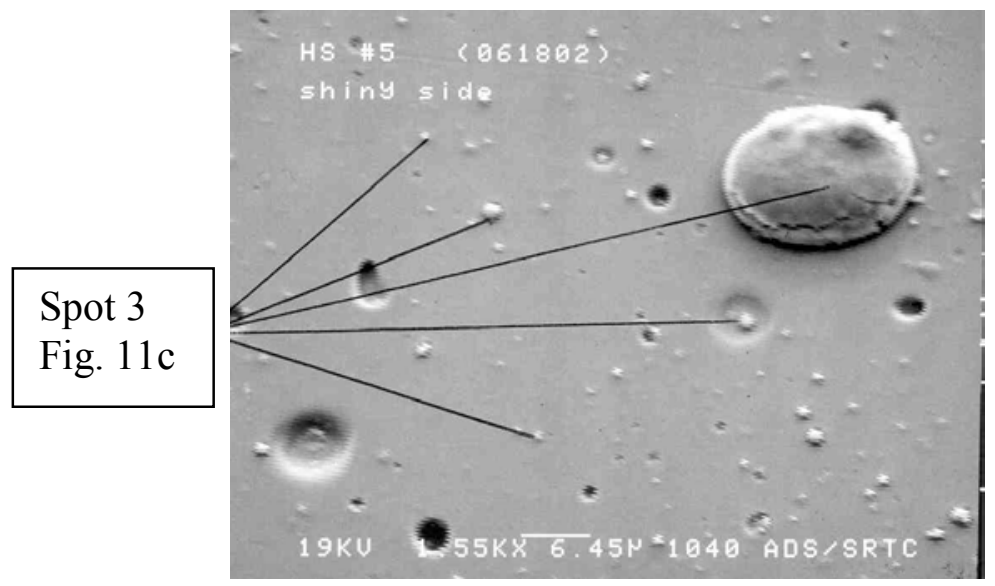

Fig 10b. SEM image of surface of $\mathrm{ZrN}$ coated sample that exhibited a near metallic white sheen

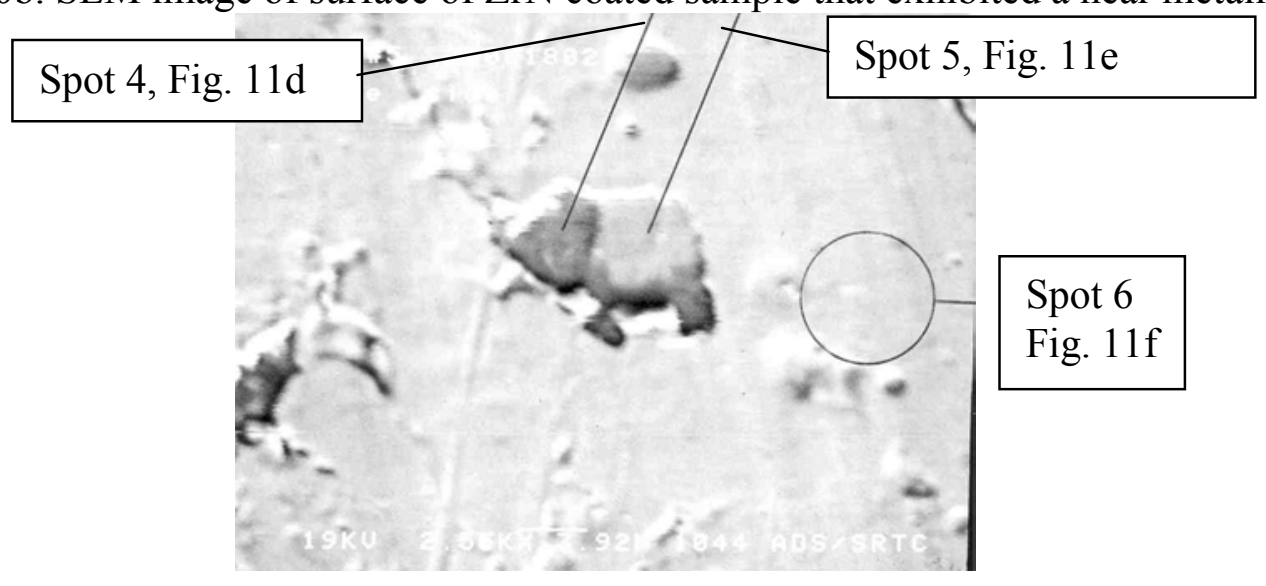

Fig 10c. SEM image of surface of $\mathrm{ZrN}$ coated sample that exhibited a blue oxide film.

Fig. 10. SEM micrograph of surface of $\mathrm{ZrN}$ coated sample that exhibited a (a) near metallic white sheen (b) near metallic white sheen and (c) a blue oxide film. XEDS data for each spot are shown in Figure 11. 
Thermo NORAN

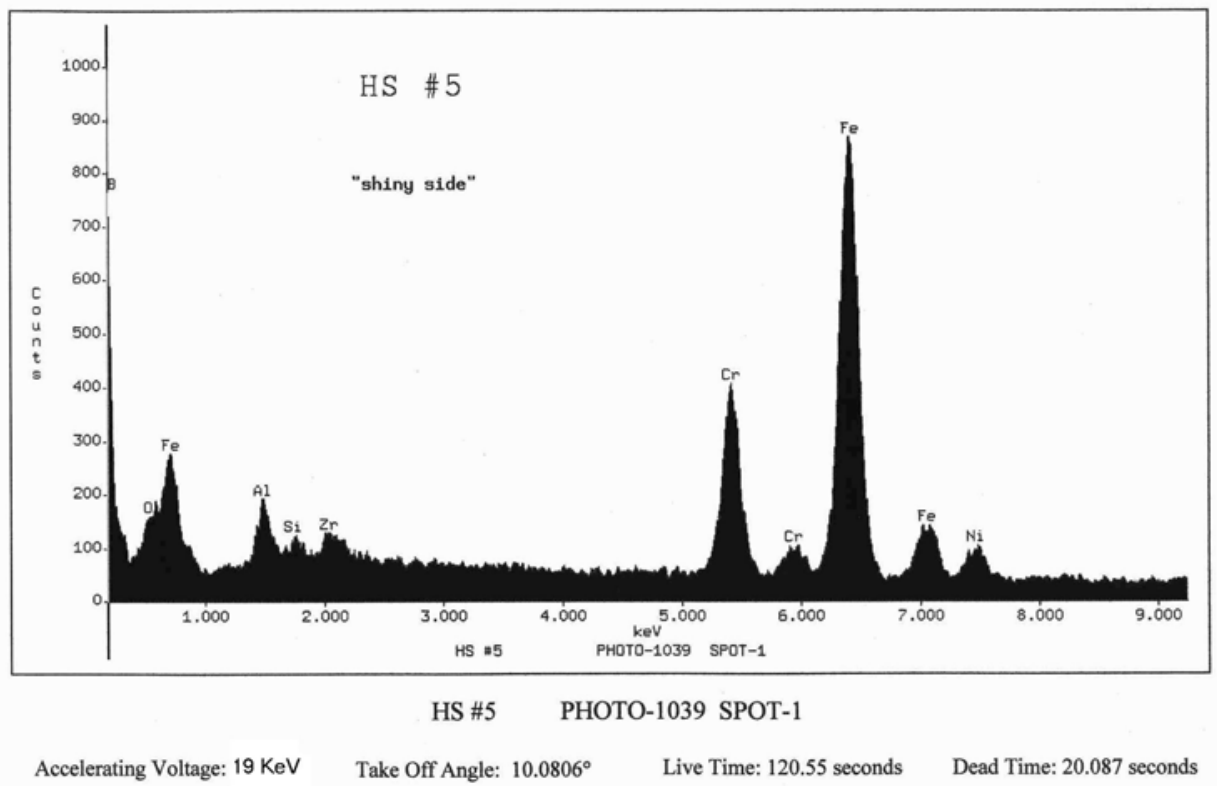

Fig. 11a. XEDS plot from spot 1 .

ThermoNORAN

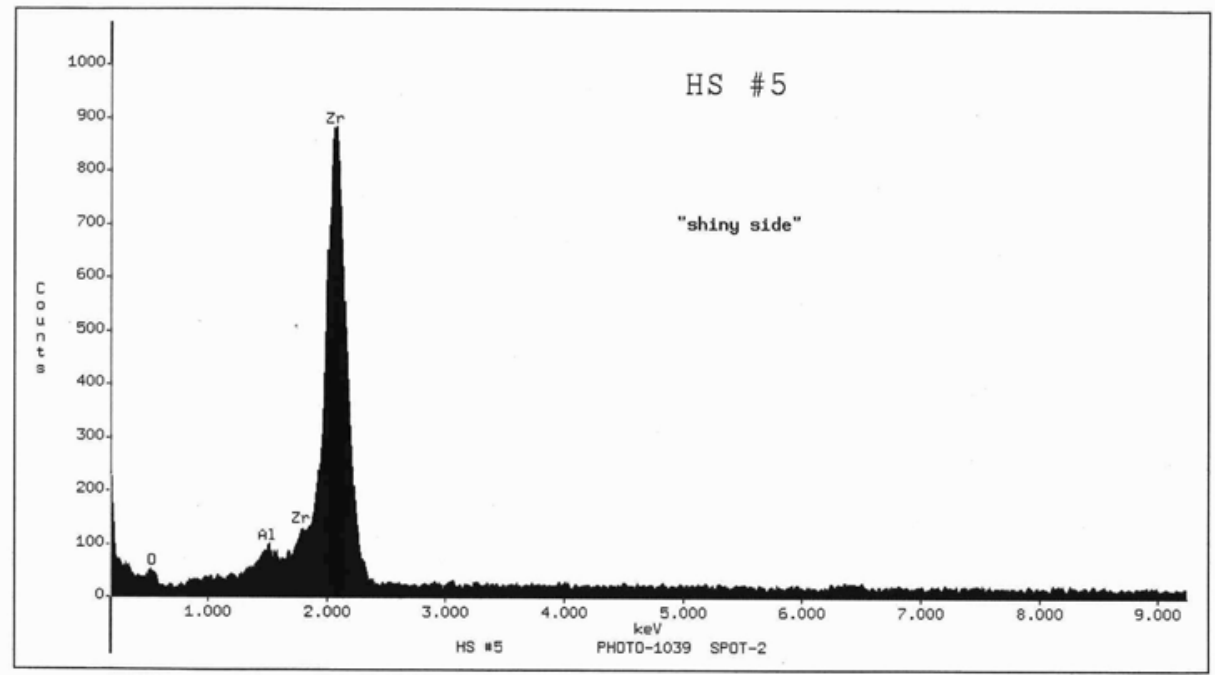

HS \#5 PHOTO-1039 SPOT-2

Accelerating Voltage: $19 \mathrm{KeV}$

Take Off Angle: $10.0806^{\circ}$

Live Time: 45 seconds

Dead Time: 8.258 seconds

Fig. 11b. XEDS plot from spot 2 
Thermo NORAN

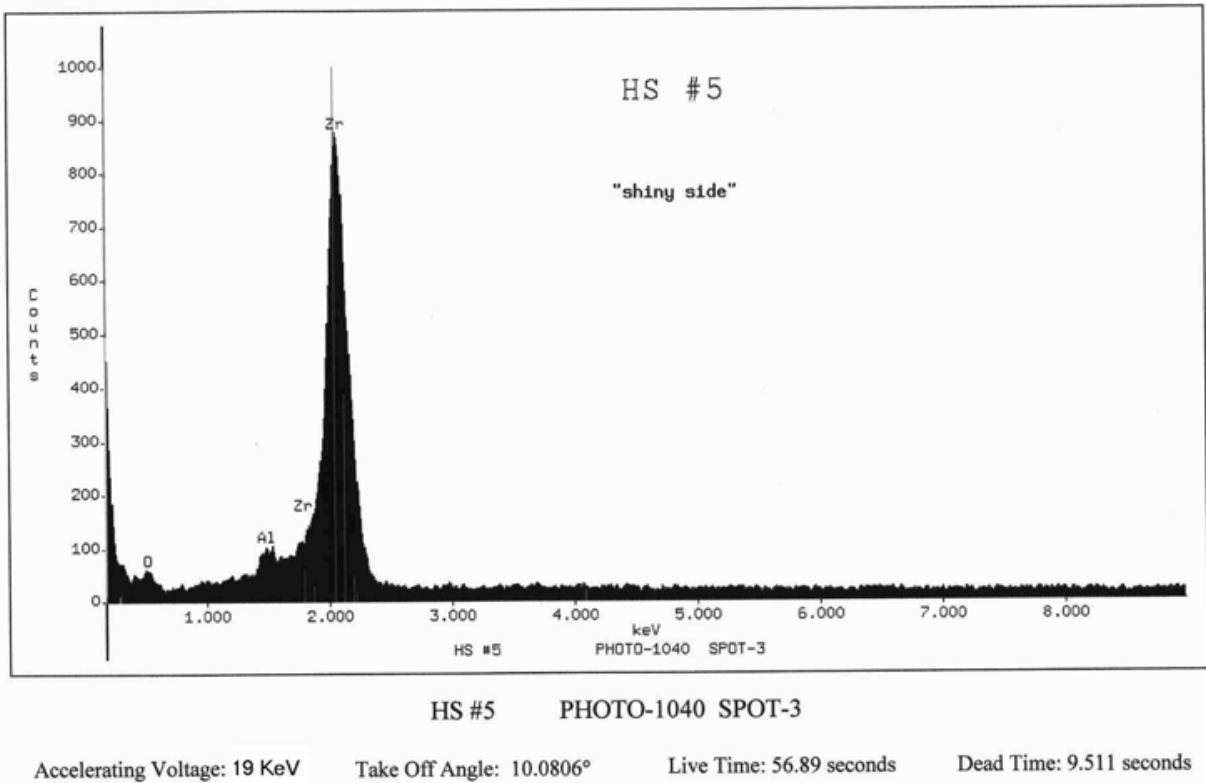

Fig. 11c. XEDS plot from spot 3.

Thermo NORAN

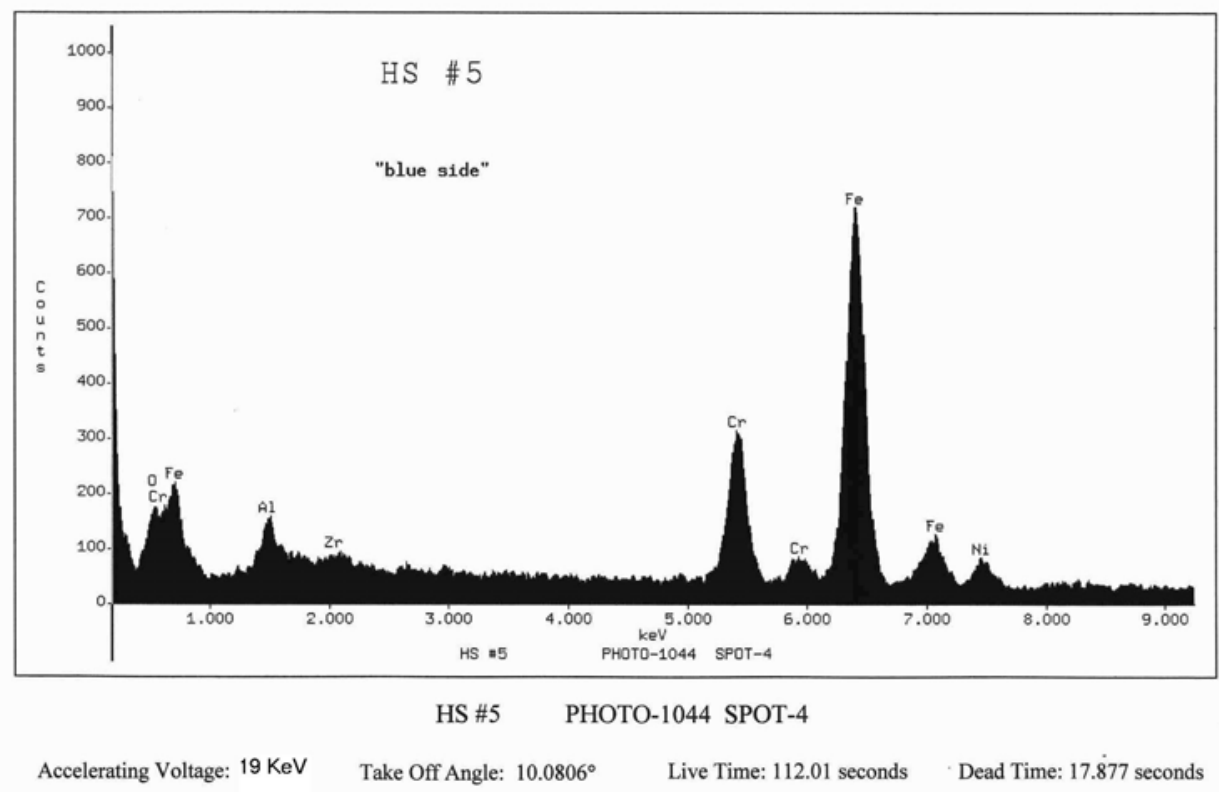

Fig. 11d. XEDS plot from spot 4. 
Thermo NORAN

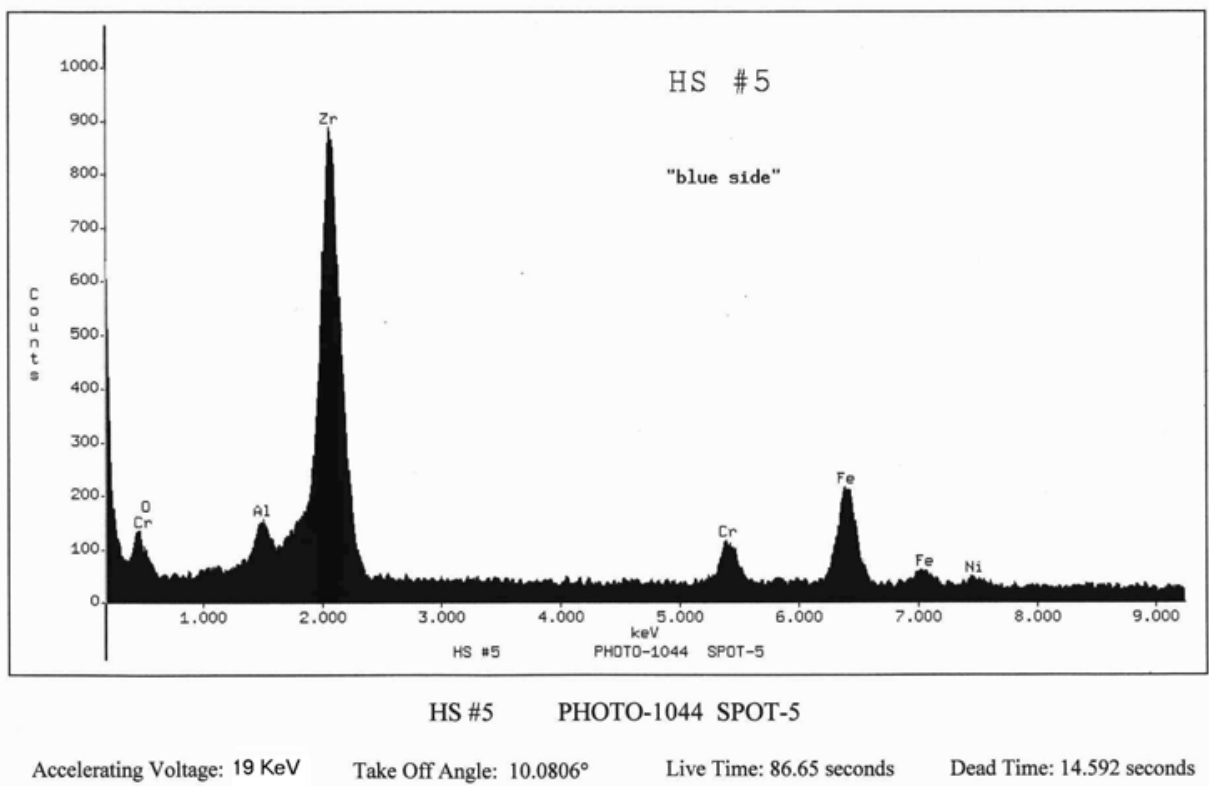

Fig. 11e. XEDS plot from spot 5.

ThermoNORAN

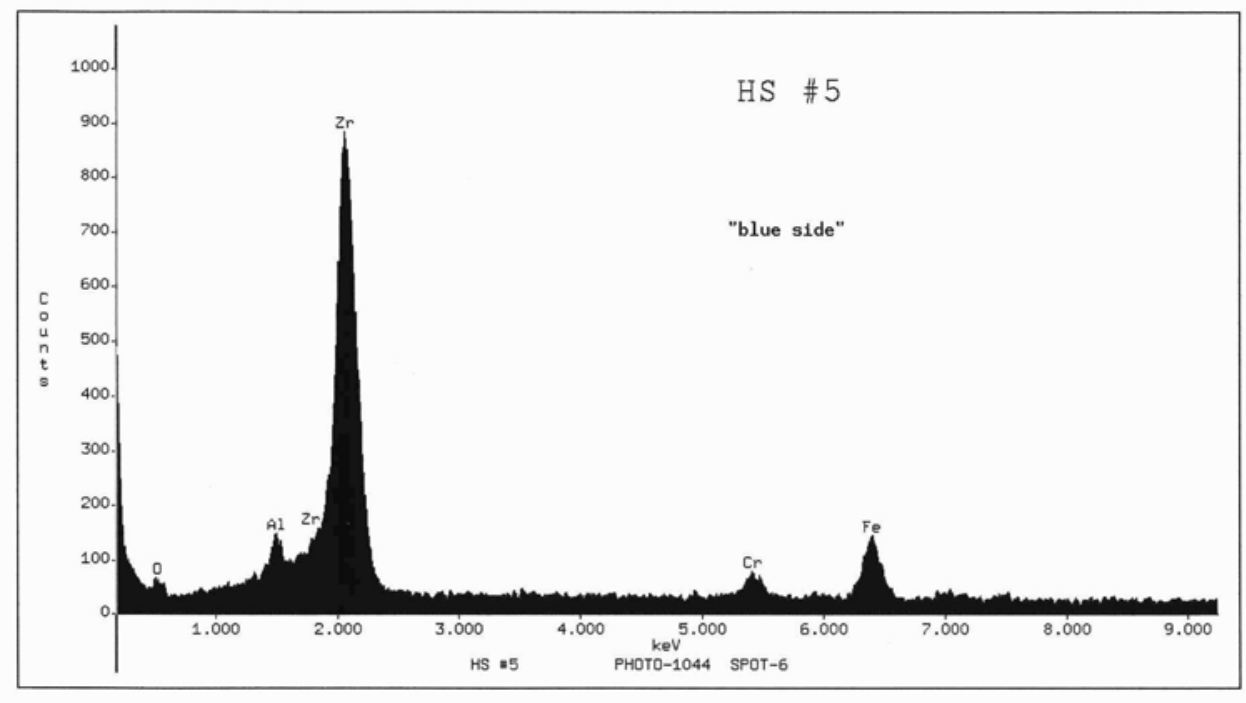

HS \#5 PHOTO-1044 SPOT-6

Accelerating Voltage: $19 \mathrm{KeV}$ Take Off Angle: $10.0806^{\circ} \quad$ Live Time: 67.96 seconds Dead Time: 12.514 seconds

Fig. 11f. XEDS plot from spot 6.

Fig. 11. XEDS plots of spots shown in Fig. 10, (a) spot 1, (b) spot 2, (c) spot 3, (d) spot 4, (e) spot 5, and (f) spot 6 . 


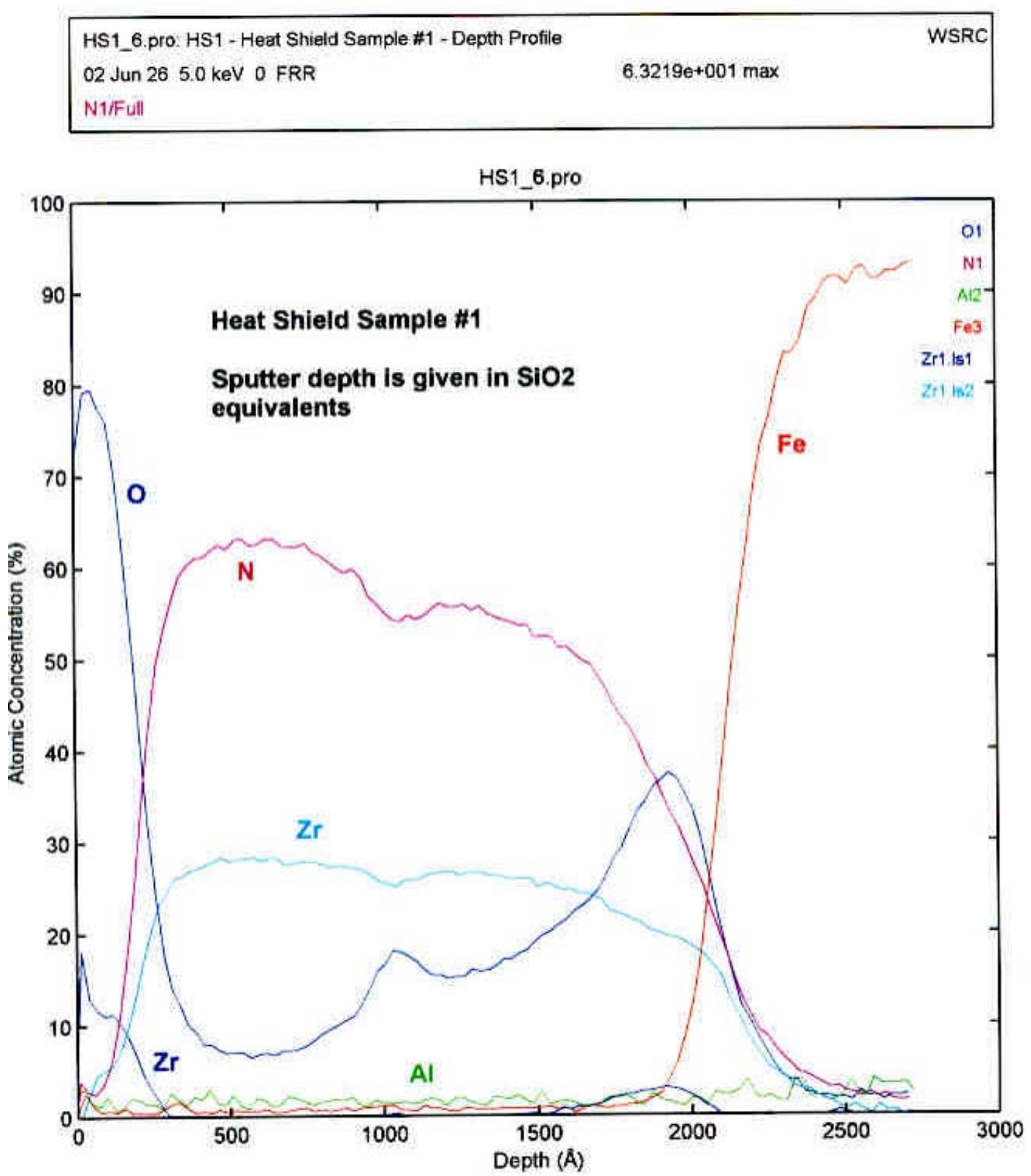

Fig. 12a. AES composition profile of $\mathrm{ZrN}$ coated mini-heat shield that exhibited gold coloration. 


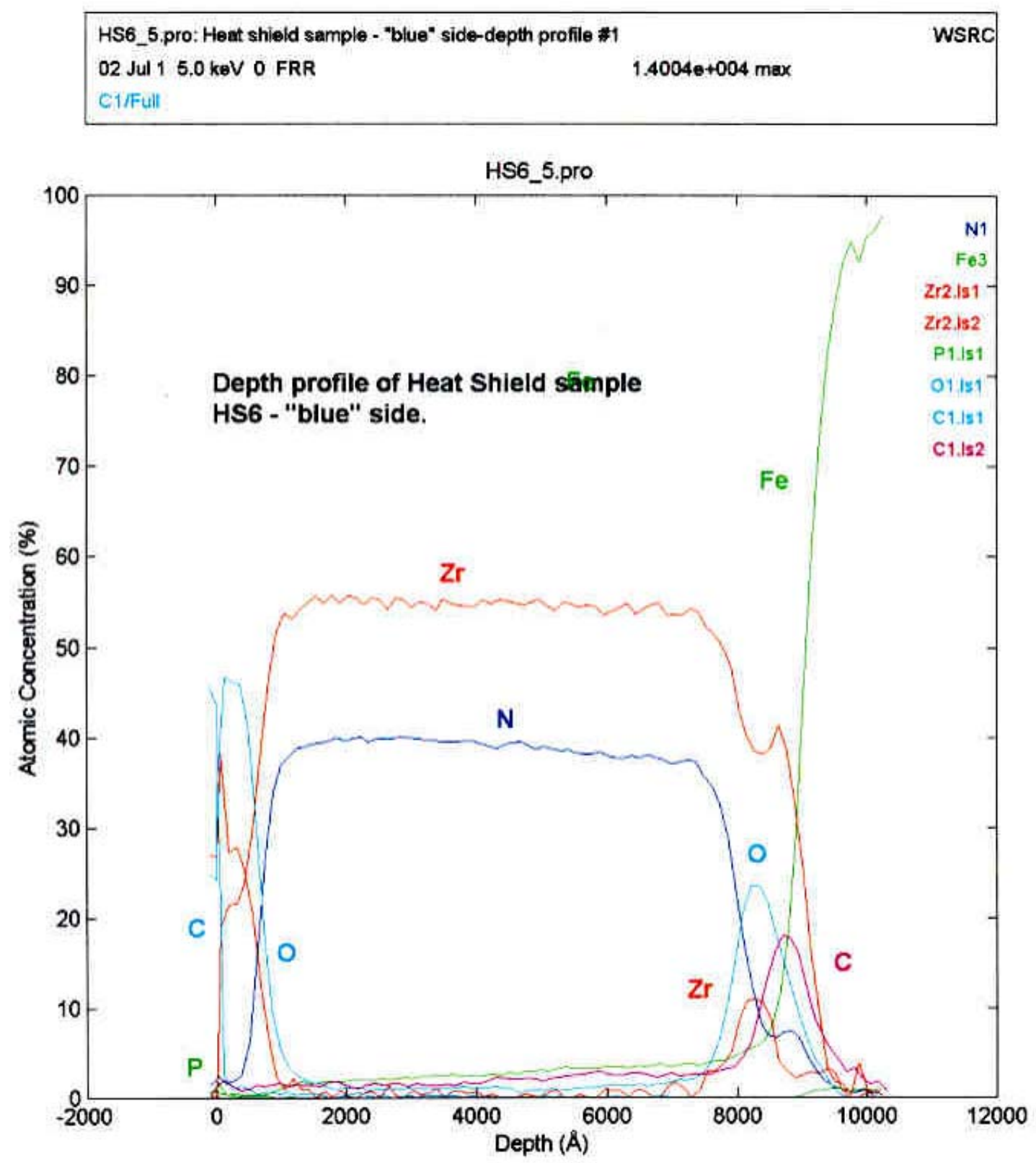

Fig. 12b. AES composition profile of $\mathrm{ZrN}$ coated mini-heat shield that exhibited blue coloration.

Fig. 12. AES composition profile of $\mathrm{ZrN}$ coated heat shield that exhibited (a) gold coloration (b) blue coloration. 
Sup1_8_1.pro: Support \#1 sample-side with writing-SEM before profile

WSRC O2 Jul $185.0 \mathrm{keV}$ O FRR

$5.15800+001 \max$

Zrifill

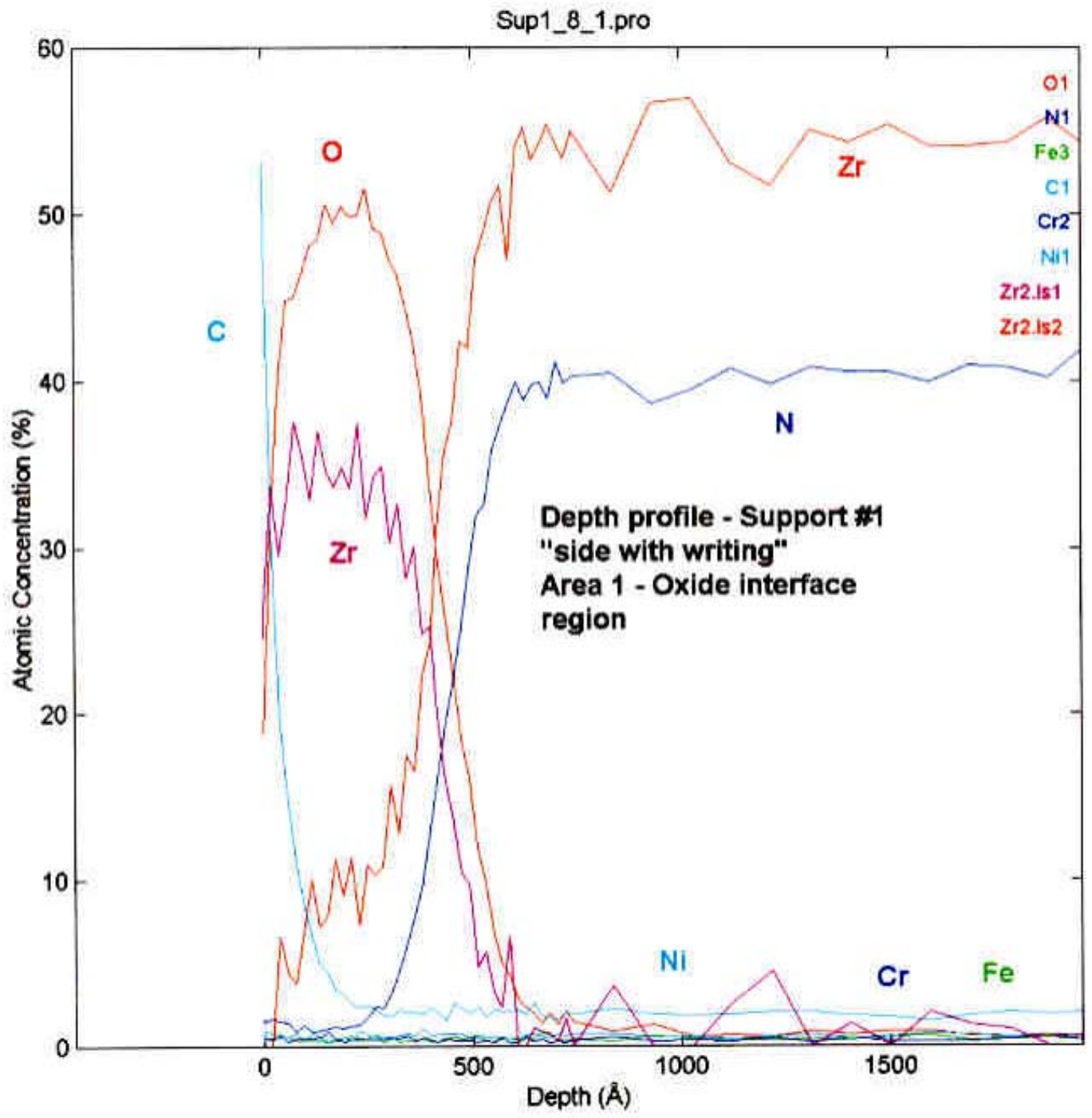

Fig. 13a. AES composition profile from gold mini-heat shield, oxide to nitride transition. 


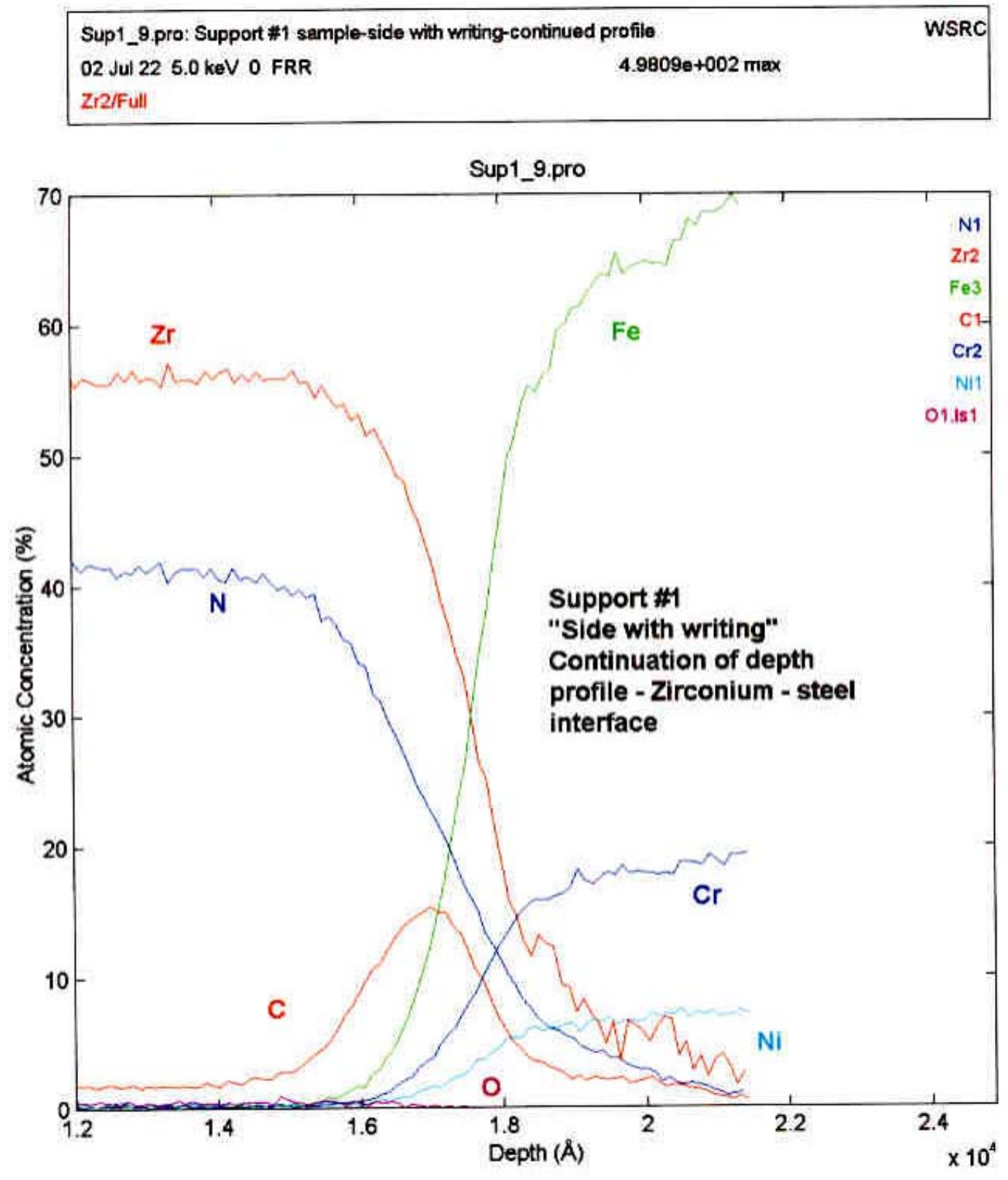

Fig. 13b. AES composition profile from gold mini-heat shield, nitride to base metal transition.

Fig. 13. AES composition profile from gold mini-heat shield (a) oxide to nitride transition (b) nitride to base metal transition. 
HS6_5.pro: Heat shield sample - "blue" side-depth profile \#1

02 Jul $15.0 \mathrm{keV}$ O FRR

WSRC

C1/Full

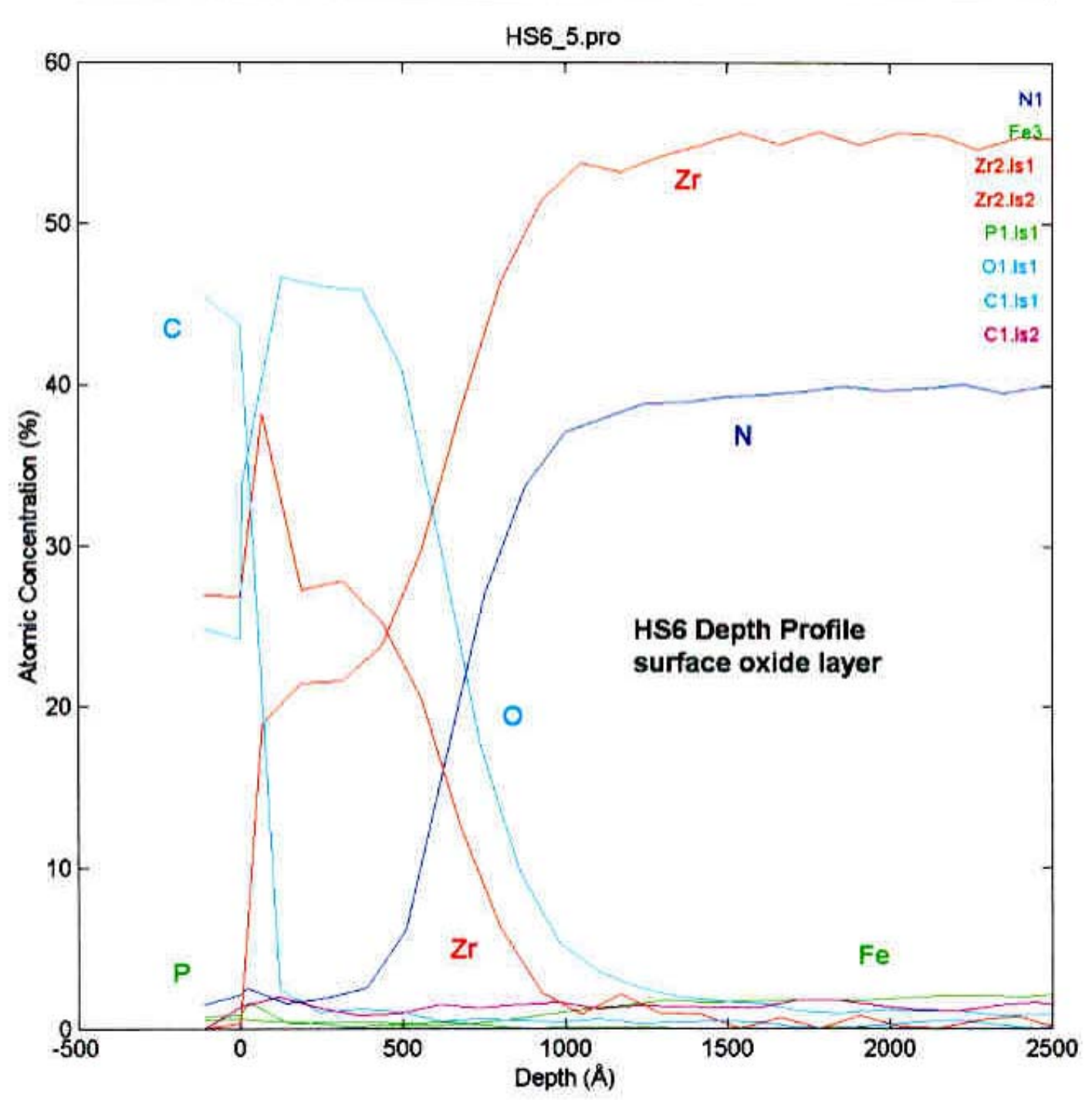

Fig. 14a. AES composition profile from blue mini-heat shield, oxide to nitride transition. 


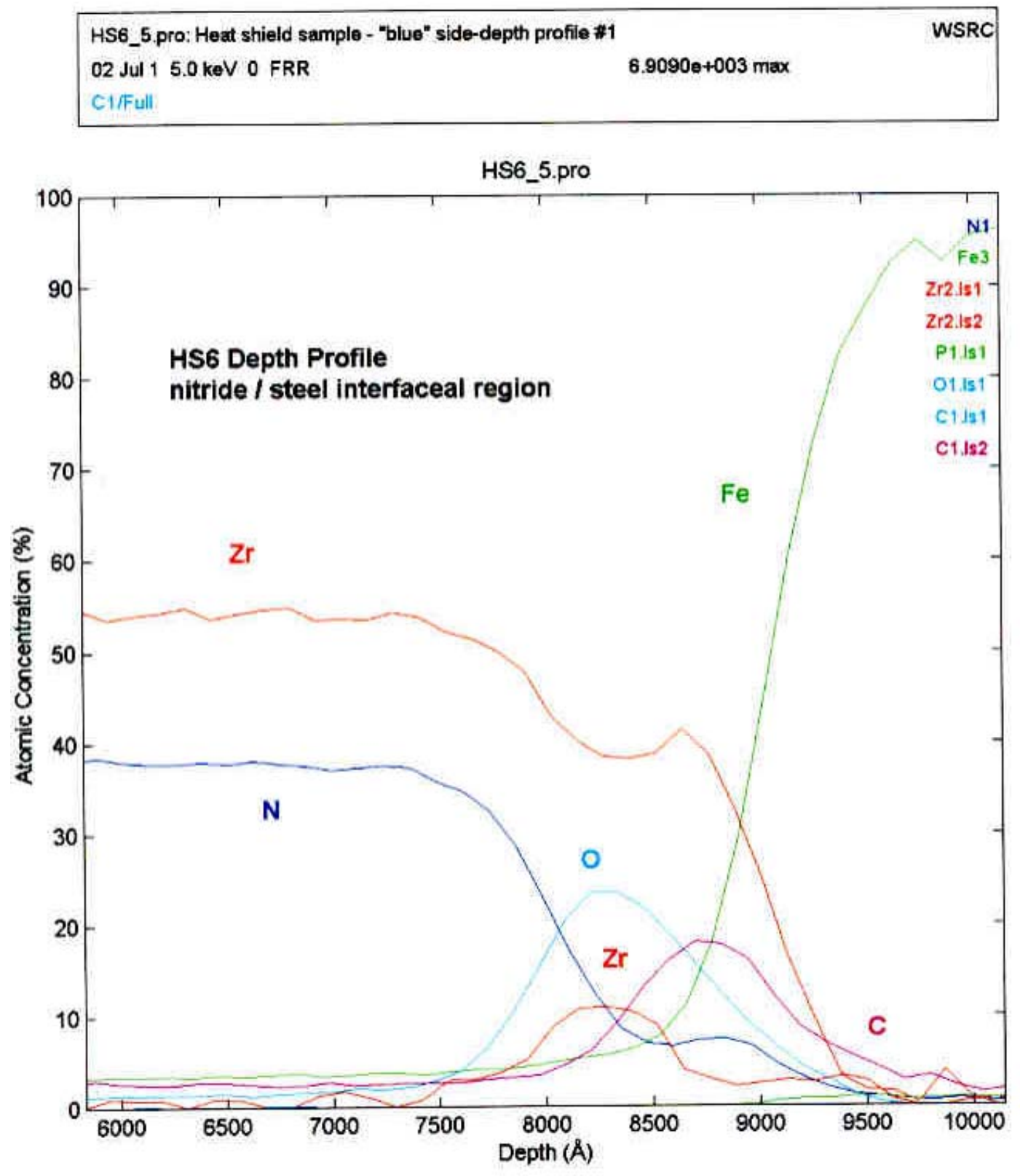

Fig. 14b. AES composition profile from blue mini-heat shield, nitride to base metal transition.

Fig. 14. AES composition profile from blue mini-heat shield (a) oxide to nitride transition (b) nitride to base metal transition 